\title{
Psychoacoustic Foundations Of Contextual Harmonic Stability In Jazz Piano Voicings
}

\author{
James McGowan
}

Considerable harmonic variation of both chord types and specific voicings is available to the jazz pianist, even when playing stable, tonic-functioned chords. Of course non-tonic chords also accommodate extensive harmonic variety, but they generally cannot provide structural stability beyond the musical surface. Many instances of tonic chords, however, also provide little or no sense of structural repose when found in the middle of a phrase or subjected to some other kind of "dissonance." The inclusion of the word "stable" is therefore important, because while many sources are implicitly aware of the fundamental differences between stable and unstable chords, little significant work explicitly accounts for an improvising pianist's harmonic options as associated specifically with harmonic stability or harmonic "consonance"-in tonal jazz.

The ramifications are profound, as the very question of what constitutes a stable tonic sonority in jazz suggests that underlying precepts of tonality function differently in improvised jazz and common-practice music. While some jazz pedagogical publications attempt to account for the diverse chord types and specific voicings employed as tonic chords, these sources have not provided a distinct conceptual framework that explains what criteria link these harmonic options. Some music theorists, meanwhile, have provided valuable analytical models to account for the sense of resolution to stable harmonic entities. These models, however, are largely designed for "classical" music and are problematic in that they tend to explain pervasive non-triadic harmonies as aberrant in some way. ${ }^{1}$

\footnotetext{
${ }^{1}$ Representative sources that address "classical" models of jazz harmony include Steve Larson, Analyzing Jazz: A Schenkerian Approach, Harmonologia: studies in music theory, no. 15 (Hillsdale, NY: Pendragon Press, 2009); Henry Martin, "Schenker and the Tonal Jazz Repertory," Tijdschrift voor Muziektheorie 16/1 (February 2011); and Steven Strunk, "Bebop Melodic Lines: Tonal Characteristics," Annual Review of Jazz Studies 3 (1985): 97-120. Representative sources that address jazz pedagogical models of jazz harmony include Wolf Burbat, Die Harmonik desJazz, 4th ed. (Munich, Germany: DTV and Bärenreiter, 1994); Andy Jaffe, Jazz Harmony, 3rd ed. (Rottenburg, Germany: Advance Music, 2009); and Bert Ligon, Jazz Theory Resources: Tonal, Harmonic, Melodic, and Rhythmic Organization of Jazz, vols. 1 and 2 (Milwaukee: Hal Leonard, 2001). For further examples, see James McGowan, “'Consonance' in Tonal Jazz: A Critical Survey of Its Semantic History," Jazz Perspectives 2/1 (May 2008): 69-102.
} 
The scarcity of work on this topic can be explained by the numerous challenges associated with jazz harmony generally. Improvised jazz is constantly in flux. Form and style may be consistent within a single performance, but even subtle deviations in expected chord choices could throw an analyst off course. The absence of an authoritative score is another practical limitation. While single-line solos can be transcribed with relative accuracy, chordal voicings of piano comping are considerably more difficult to transcribe; available published transcriptions should best be treated as only approximations of the actual notes played. In addition, there is little consensus among jazz theorists as to methodology, so this sub-discipline has not had an established, generally accepted theory from which to work.

Given all these factors, the theoretical literature has had difficulty explaining how tonal structure in jazz compares to that of common-practice classical music. Perhaps the most significant stumbling block, from the perspective of commonpractice tonal theory, is how to interpret stable jazz chords that are greater than a triad. As I wrote in a related article, "Referring to such harmony as 'dissonances' obscures the analysis of jazz as tonal music, for it assumes that standard jazz chords serving as syntactically stable harmonies require further resolution (which they never receive)." 2 To develop a stylistically sensitive conception of jazz tonality, we must reevaluate basic theoretical assumptions, including our understanding of what constitutes stable and unstable sonorities.

This study accounts for one part of a conception of stable harmony in tonal jazz: the vertical dimension. (The horizontal dimension, including harmonic succession, voice leading, syntax, and rhetoric, is equally critical but falls beyond the present scope.) I will attempt to critically evaluate what can be taken from previous research in tonal theory and applied within a jazz perspective. Specifically, I propose: 1) an expanded concept of harmonic dialects that accounts for variants in chordal membership of stable sonorities; and 2) an outline of psychoacoustic phenomena that affect how various piano voicings are interpreted as stable or unstable in different contexts. This study builds on the work of a few prominent jazz pedagogues and music theorists, and provides musical examples and graphic models that represent the union of both ideological traditions.

In the article quoted above, I argue that "consonance and dissonance refer to stable/passive and unstable/active harmonic entities within the musical grammar of a distinct cultural system, as influenced by sonorous euphony." That article defined and justified a conception of consonance specifically for tonal jazz, constructed from sources in the fields of jazz theory and the history of music theory. This conception-which blends the vertical and harmonic dimensions-invokes the metaphors of instability and motion to explain dissonance, and stability and repose

\footnotetext{
${ }^{2}$ McGowan, “Consonance' in Tonal Jazz,” 71.

${ }^{3}$ Ibid.
} 
to explain consonance. Because the present article focuses only on the vertical dimension of the "consonance/dissonance" construct, I will use the term "harmonic stability" instead of "consonance" to reflect this restricted scope. Further, the terms "stable" and "unstable" are generally less politically charged in the discipline of music theory and are effective in this semantic context.

In determining the harmonic stability or instability of tonal jazz in the vertical dimension, individual sonorities are addressed in two principal ways: as a set of possible chords grouped within stable harmonic dialects, and as sonorous entities of variable euphony based on psychoacoustic implications of their voicing (or loosely, how stable the voicings sound). The theory of harmonic dialects, as outlined below, encompasses characteristic components of chordal membership and configurations in pitch space. The topic of voicings is addressed afterwards.

\section{HARMONIC DIALECTS}

The repertoire of tonal jazz includes a variety of options for stable harmonies. The present study groups the many potentially appropriate chord voicings into distinct sets of chord-tone memberships and larger classes called harmonic dialects. My use of the term "dialects" is meant to embrace the analogy frequently made between language and music, and to recognize that analytical tools and explanatory models from sociolinguistics can be readily applied to the study of comparable phenomena in tonal jazz. ${ }^{4}$

This study proposes that there are three principal dialects in tonal jazz: the added sixth, the minor seventh (blues seventh in major keys), and the major seventh. The triad also remains a viable (albeit unlikely) option for stable harmony, and in modern jazz, ninth and eleventh/ninth extensions may be added to the principal dialects as suffixes. Example 1a illustrates these dialects for a major key, and the dialects for a minor key are shown in Example $1 \mathrm{~b}$.

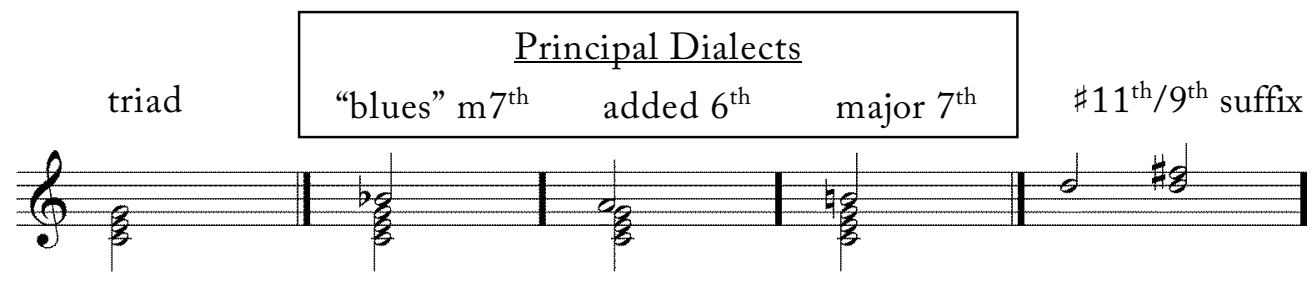

Example 1a. Stable harmonic dialects in major.

${ }^{4}$ I originally referred to this approach to categorization as Consonant-Tonic Dialects; see James McGowan, "Understanding Jazz Styles through Sociolinguistic Models," Discourses in Music 4 (Fall 2002). An outstanding source that analyzes jazz improvisation by analogy to sociolinguistic dynamics of conversation is Ingrid Monson, Saying Something: Jazz Improvisation and Interaction (Chicago: The University of Chicago Press, 1996). 


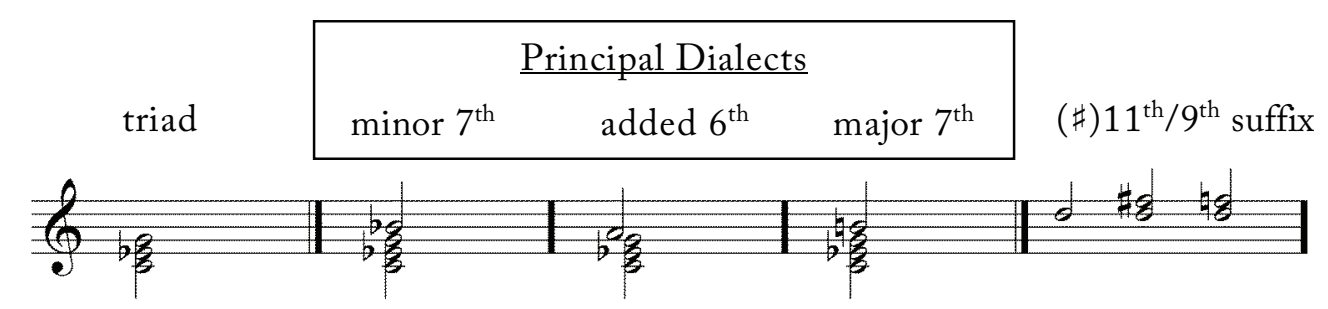

Example 1b. Harmonic dialects in minor.

Adapting terms from Steve Larson's work, ${ }^{5}$ this study refers to members of the triad as inherently stable chord tones, or triadic tones. Illustrated graphically as half notes with stems down, triadic tones act as the core stable elements in each harmonic dialect. The three principal dialects are differentiated by contextually stable chord tones, or dialect tones, indicated by half notes with stems up. Dialect tones are both stable and chord tones, but only in their own tonal environments. For example, in the major-seventh dialect, the minor seventh is neither a chord tone nor contextually stable. The three principal dialects can be extended to include ninths and, less often, sharp elevenths as contextually stable chord tones. In many musical situations, however, ninths and sharp elevenths are relatively stable, neither requiring resolution nor functioning as true members of the chord. These color tones supplement the active chord tones of the dialect, much like a suffix supplements a root word without changing its underlying meaning. When a ninth (or sharp eleventh/ninth) occurs as a dialect tone or color tone, it acts like a chordal suffix to one of the principal dialects. Thus, in this theory, the three types of stable tones-triadic tone, dialect tone, and color tone-combine to create "sensuous" sonorities with varying cardinality of stable tones. ${ }^{6}$

As seen in Example 1b, the harmonic dialects in minor keys are the same as in major keys with two exceptions. First, whereas the major-minor seventh dialect (another term for the "blues-seventh dialect") generally appears only in the context of blues, the minor-minor seventh dialect can be found in a variety of styles. Second, regarding the eleventh/ninth suffix, the natural eleventh is restricted in major but not in minor. In minor either the natural eleventh or, less commonly, the sharp eleventh can be used, because neither pitch creates a minor ninth interval

5 These terms, though inspired from the work of Steve Larson, have been expanded to be conceptually consistent with the theory of harmonic dialects. Steve Larson, "The Problem of Prolongation in Tonal Music: Terminology, Perception, and Expressive Meaning," Journal of Music Theory 41/1 (1997): 101-36.

6 "Sensuous" and its corollary "kinetic" refer to different motivations of harmony, as defined by Meyer, and influenced by Kurth. See Leonard B. Meyer, Music, the Arts, and Ideas (Chicago: University of Chicago Press, 1967), 34-53; and Ernst Kurth, Selected Writings, translated by Lee Rothfarb (Cambridge: Cambridge University Press, 1991). 
above the flat third (a constraint of voicing, discussed below). Despite differences between major and minor dialects, both ultimately feature only three options for dialect tones: the major sixth, minor seventh, and major seventh above the root.

Determining whether a chord member is a dialect tone or color tone is mostly a matter of analytical interpretation, particularly regarding the ninth. ${ }^{7}$ How the note appears, and what comes before or after, are critical contextual factors. If the tone is played in a disproportionately high register, it is likely a color tone. If the tone does not participate in voice leading, it is best interpreted as a color tone. If the tone is treated as an arrival note in a melodic line, it should be analyzed as a dialect tone. Any such determination can be cross-referenced against clearer examples by the same pianist in similar contexts. Further, timbre and tuning play a role in determining the relative stability of extensions (or any interval). ${ }^{8}$ In Example 2, the ninth is depicted as a dialect tone and as a chord tone in two principal dialects, one major and one minor.

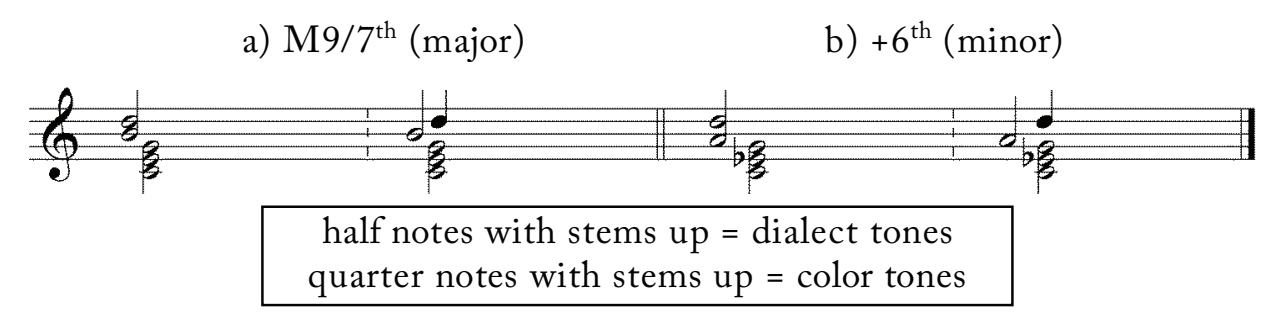

Example 2. Interpreting stable ninths as dialect or color tones.

Beyond the stable chord tones, this theory proposes that three types of unstable tones can destabilize a sonority. A contextually unstable non-chord tone is akin to Kirnberger's unessential dissonance. ${ }^{9}$ Unlike color tones, which need not be resolved, these non-chord tones serve the same purpose in jazz as in classical music: to create tension and require resolution (in the manner of a suspension). A contextually unstable chord tone is comparable to Kirnberger's essential dissonance. In the context of classical music, a minor seventh above the root of a dominant seventh chord

\footnotetext{
${ }^{7}$ The inclusion of the ninth in chordal vocabulary—common but not essential—varies according to synchronic state, pianist, and style. In contrast, the sharp eleventh, when stable, is usually a color tone.

${ }^{8}$ Close investigation of the specific role of timbre in perceiving consonance is beyond the scope of this study. For an introduction to the issue, see William A. Sethares, Tuning Timbre Spectrum Scale, 2nd Ed., (London: Springer Verlag, 2005).

${ }^{9}$ Johann Philipp Kirnberger, The Art of Strict Musical Composition, translated by David Beach and Jurgen Thym, introduction and explanatory notes by David Beach (New Haven, CT: Yale University Press, 1982), 44-45.
} 
creates an essential dissonance in the chord, necessitating a change of bass upon resolution. In jazz, chords of resolution that emphasize the triadic, added-sixth or major-seventh dialects can be preceded by unstable chords that include the essential minor seventh. This chord tone is not always unstable, however, because majorminor sevenths can be contextually stable in blues-seventh dialects. Context determines not only which notes are stable in a harmonic dialect (beyond the triad) but also which notes are unstable in other chords. As a result of this variability, the stability of jazz harmony is distinguished by many features of sonority and function. The third type of unstable tone is the inherently unstable tone, which always adds tension to otherwise stable sonorities and is carefully avoided in regular situations. Inherently unstable tones include notes that sound a minor sixth and a minor ninth above the root, as well as a perfect eleventh above the root in major and a major tenth above the root in minor. ${ }^{10}$

This article proposes that these harmonic dialects are the normative harmonies of tonal jazz at moments of expected syntactic repose. These moments generally correspond to the stable tonic chords found in the composition being performed, particularly at authentic cadences, but also include other harmonies serving as temporary tonics. At these distinct places in the form, listeners expect to hear functional resolution to stable harmony. This realization may be thwarted, of course, by a performer manipulating this musical expectation. Jazz musicians intentionally and constantly alter and evade stable tonic harmony in the original tune, creating new harmonic and formal structures that impact the dynamic intensity of each moment and the sustainability of solo choruses. When relative repose is finally desired, performers generally employ one of the harmonic dialects, realized in an appropriately stable voicing.

\section{HARMONIC DIALECTS IN STYLISTIC CONTEXTS}

Besides chordal membership, another aspect of musical phonology is a chord's sonorous euphony, or perceived consonance (contextual "pleasantness") based on sensory criteria. Many factors influence the perception of relative consonance and dissonance in individual sonorities, including articulation, timbral alteration, durational emphasis, metric placement and displacement, dynamics, embellishments of chord tones, mode, and resonance. A chord's voicing is also one of the most significant features affecting euphony. Several qualities of chord voicings affect how the chord "sounds" in pitch space: range (high or low placement);

\footnotetext{
${ }^{10}$ Note that in unstable harmony, these tones can be chord or non-chord tones, depending on the situation. In stable sonorities, these tones can be included as chord tones only in limited circumstances, such as when the tones mimic the overtone series as part of tonal hyperbole (discussed below). Otherwise these tones tend to destabilize the sonority.
} 
spacing between chord tones; use of specific pitch intervals; and configuration and duplication of pitch-classes. All of these important factors contribute to the degree of stability of a chord, and may cause listeners to reinterpret stable chords as unstable. But these factors also interact to help determine the harmonic dialect evinced at a moment of syntactic repose. Performers use these salient musical elements to control the dialect tones and color tones in effect at any given point.

The impact of all these factors on chord stability and harmonic dialect is stylistically contextual and very open to personal interpretation by the analyst. While most of the factors discussed below are explicitly mentioned in existing secondary sources, some criteria relating psychoacoustics to jazz piano practice have been inferred or adduced here. Let us consider a few analytical vignettes. Harmonies are considered as independent structures in this section, even though voice leading and balance between harmonies are integral to recognizing dialects and perceiving stability in sonorities. $^{11}$

Consider Example 3, a transcribed excerpt of an Art Tatum performance. The expected cadential arrival is metrically displaced, appearing midway through beat 3 of the penultimate measure. The harmonic emphasis arising from this syncopation is further stressed by the conventional durational accent of the final chord. Even without considering issues of syntax and context, ${ }^{12}$ this example unequivocally denotes the major-seventh harmonic dialect. The four notes of the chord are presented clearly and economically, and the major seventh (D) is subsequently reinforced in multiple octaves, underscoring this dialect tone's role as an integral and stable member of the chord.

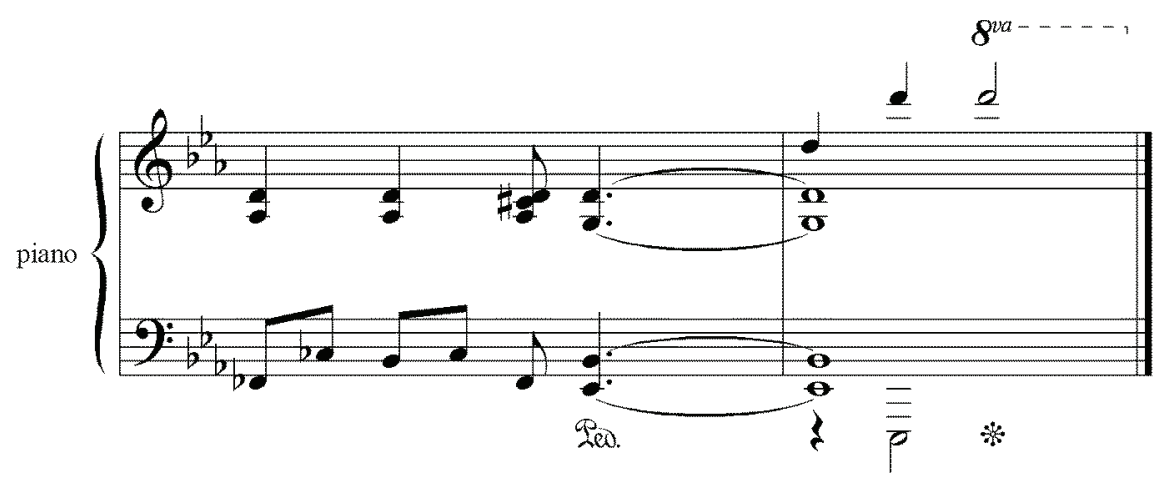

Example 3. End of "Ain't Misbehavin'" as played by Art Tatum (December 29, 1953).

11 "In short, after the desired harmonic structure has become established, voicing becomes the melodic treatment of all individual lines, simultaneously." Bruce Benward and Joan Wildman, Jazz Improvisation in Theory and Practice (Dubuque, IA: Wm. C. Brown, 1984), 161.

${ }^{12}$ This discussion focuses on salient factors within the extended harmonic area itself, and does not consider voice leading or dialect usage elsewhere in the piece. Both of these factors reinforce that $\mathrm{D}$ is indeed a dialect tone in the major-seventh dialect. 
Example 4 shows the ending to "Russian Fantasy," as recorded by Fats Waller in 1935. Here, the major seventh is not heard as a dialect tone (even though careless transcribers often provide chord symbols based on apparent chords on the downbeat). Rather, the $B$ clearly serves as an upper neighbor to the $A$, while the $G \sharp$ is a lower neighbor to the A. In some scenarios, non-chord tones that emulate different dialects create ambiguity. But in this example the non-chord tones highlight the salience of the sixth in the chord, solidly asserting a major added-sixth harmonic dialect. ${ }^{13}$

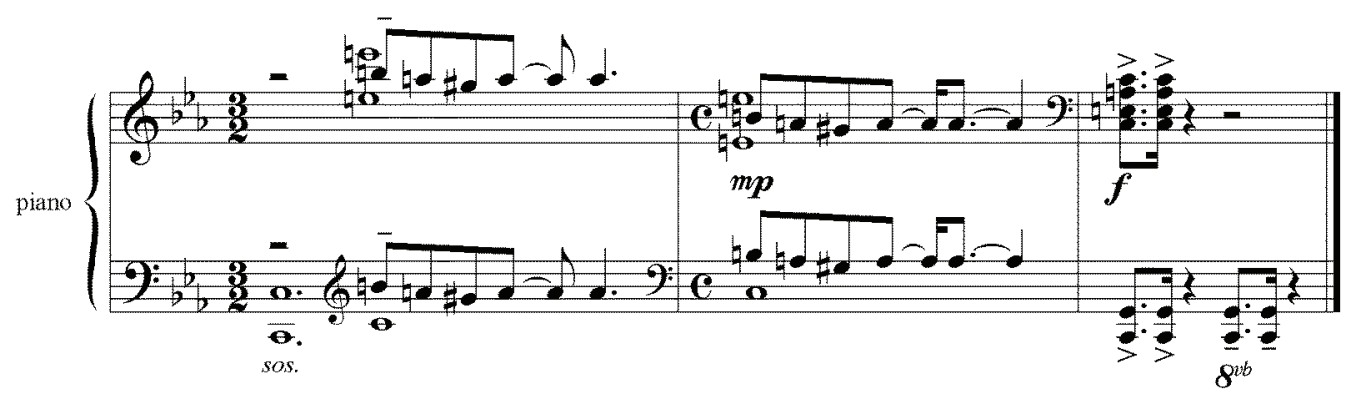

Example 4. End of "Russian Fantasy" as played by Fats Waller (March 11, 1935).

Even at moments of syntactic repose, the harmonic dialect may be obscured by rhetorical strategies. As shown in Example 5, Oscar Peterson's performance of his up-tempo composition "Place St. Henri" ends crisply with two off-beat tonic "punches," first doubled and then quadrupled in register. This presentation of a solitary pitch class is tonally convincing as an ending, but the choice of dialect is far from clear. Such cases of an under-determined harmonic dialect can be solved by considering other harmonic realizations of stable chords and obvious dialect markers. Peterson's use of a blues scale here, for instance, suggests a blues dialect. Dyads and triads are safely considered under-determined, especially at cadences. Labeling a chord or note "under-determined" is not a negative value assessment, only an acknowledgement that a particular chord is incomplete. ${ }^{14}$

\footnotetext{
13 This example also features a Picardy-third ending, which is atypical for tonal-jazz pieces. Perhaps Waller conceived this modal change as another reference to "Russian" music.

${ }^{14}$ This is commonly practiced by musicians in the midst of performance, because too much harmonic activity at a moment of consonance detracts from the overall linear momentum.
} 


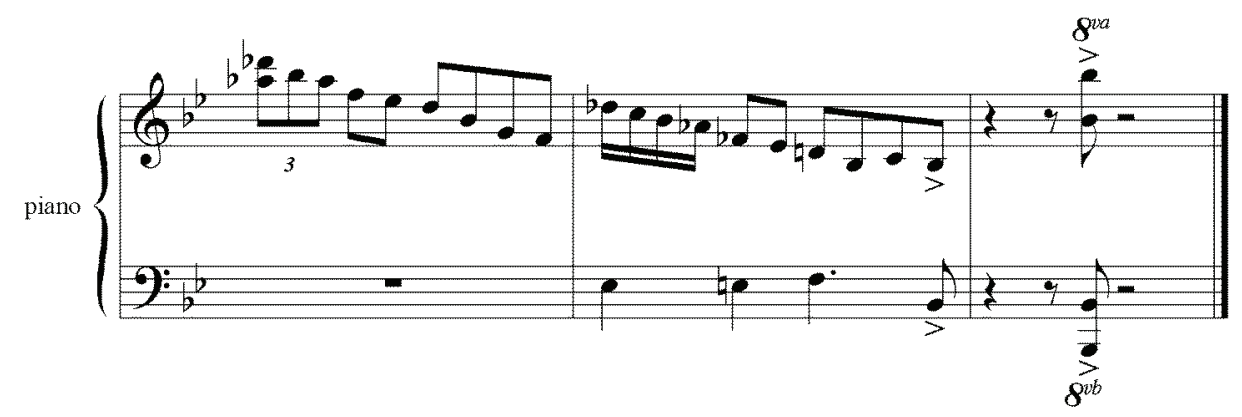

Example 5. End of "Place St. Henri" as played by Oscar Peterson (September 9, 1964).

Scalar or other decorative figures within an elaborated stable harmony can also create ambiguity of dialect, particularly with regard to extensions. Consider Example 6a, the conclusion of "How Deep is the Ocean?" as played by Bill Evans in a live trio performance on July 7, 1964. Considering only this one elaborated chord in isolation, a number of factors signal a contextually stable major-seventh chord. First, the tonic $\mathrm{E} b$ is clearly articulated at the beginning and ending of the gesture as the nadir pitch $(\mathrm{E} b 2)$ and at the apex of the left-hand scalar figure $(\mathrm{E} b 5)$. In the final chord, the fifth supports the tonic in both the left and right hands, while the third and major seventh are prominent in the right hand.

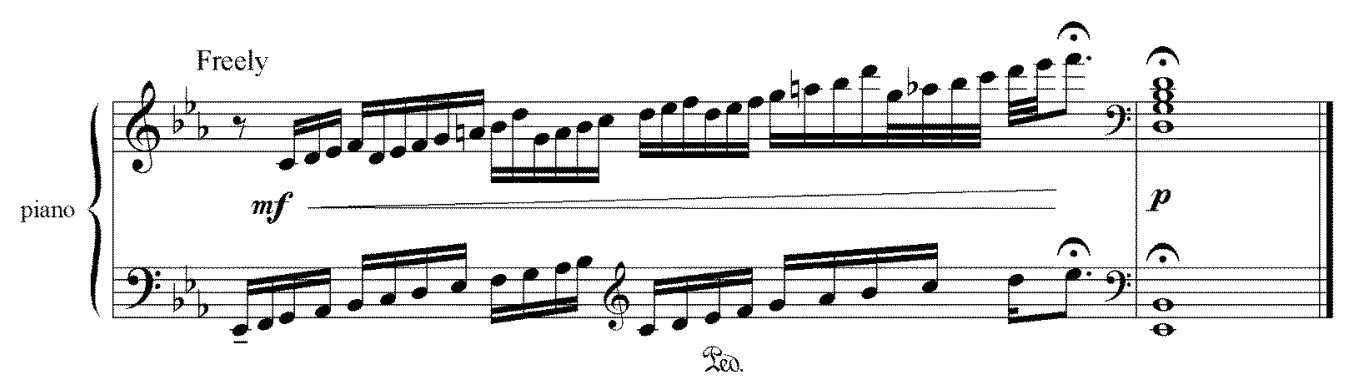

Example 6a. End of "How Deep is the Ocean?" as played by Bill Evans (July 7, 1964).

As seen in Example 6b, Evans's right-hand virtuosic passage emphasizes certain notes via skips and contour change. Square brackets show the salience of the major seventh (D) at the beginning and end of both the second and fourth segments of the run. The rectangle-boxed Gs capture the significant third of the chord, approached by a leap of a fifth and change of direction. The triangles capture fifths that are only slightly accentuated by the leap that follows them. Besides the D and $\mathrm{G}$, the only other strongly stressed pitch class is the F. The three Fs highlighted with circles are successive apex pitches emphasized by changes in direction. The concluding $\mathrm{F}$, the highest pitch of the final three minutes of the performance, is 
emphasized further by an agogic accent. In the quick brilliance of the run, Evans's right hand plays $A \nvdash$ while his left hand plays $A b$ : a subtle effect, yet barely noticeable.

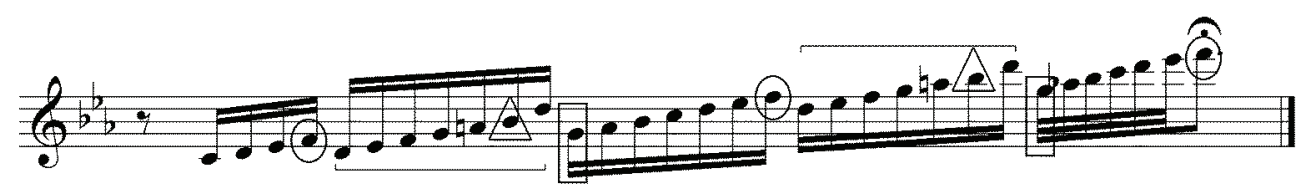

Example 6b. Analysis of right-hand passage.

The prominence of the F, particularly pitch F6, brings the chordal ninth to the fore, but it is difficult to determine whether this note serves as a dialect tone, a color tone, or perhaps even an unstable non-chord tone requiring resolution (noting, for example, the classic double-neighbor figure $\mathrm{E} b-\mathrm{F}-\mathrm{D}-\mathrm{E} b$ appearing at the beginning and middle of the passage). An important clue helps to rule out the last possibility and identify the note as a stable tone. With the pedal depressed, F5 and F6 are sustained to the end of the recording, still present while the final stablesounding major seventh is played soft and sustained. Because the ninth is not rearticulated in the final chord, it could be interpreted as a color tone, along with the sharp eleventh. Both pitch classes $\mathrm{F}$ and $\mathrm{A} \sharp$ appear as part of an accumulated sound mass of the stable closing sonority. But such an assessment would be premature without taking into account voice leading from the chord's preceding dissonance, and prior appearances of the chord in the piece as a whole.

\section{VOICING AND EUPHONY}

The final chord of Example 6a sounds stable and provides suitable closure in the major-seventh dialect of tonal jazz. What other chordal voicings can also convey a relatively strong sense of stability? In many cases, the voicing of chords is more important than the actual membership of chord tones. Pianists generally play a wide variety of voicings in stable chords, with or without the ninth. Compare the pairs of voicings in Example 7. The addition of the ninth adds richness to the sonority, harmonizes scale-degree $\hat{2}$ with a stable tonic chord, and helps create desirable voicings in fourths. ${ }^{15}$ However, interpreting whether the ninth is a dialect tone or color tone is largely guesswork unless one sees (or hears) how it appears and what

\footnotetext{
${ }^{15}$ The aesthetics of chord voicings is a topic on its own. Voicings with fourths became indispensable to modern jazz pianists such as Bill Evans. Examples of classic voicings in fourths include the "So What" chords played by Evans under the leadership of Miles Davis.
} 
comes before and after it. Relevant contextual issues could include which other stable chords have been used, whether the note is approached by voice leading, and whether the note is treated as an arrival note in a melodic line.

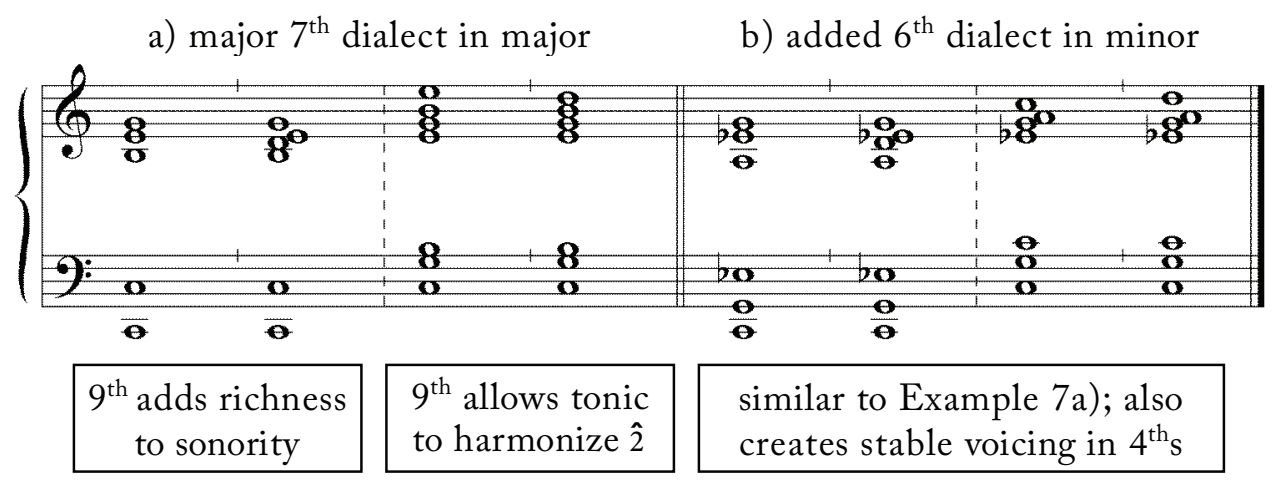

Example 7. Comparing similar voicings with and without the ninth.

Preferred voicings vary among individuals and sub-styles. The following list, summarized from a few prominent sources, outlines aspects of jazz piano voicing that are especially relevant to creating stable chords. ${ }^{16}$ Example 8 then illustrates the components of these guidelines in a variety of dialects.

1. Intervallic structures in voicings include fourths, thirds, or seconds, which, respectively, create "open," "full," and "tense” sonorous effects. Voicings regularly feature combinations of these intervals, and members of the chord are often registrally displaced. ${ }^{17}$ See Examples $8 \mathrm{a}, \mathrm{b}$, and c.

2. Thirds and sevenths (or sixths) are necessary in voicings, whereas other members are optional. The chord root is generally played, but can be omitted if playing with a bass player or moving through predictable chord progressions, such as descending fifths. ${ }^{18}$ See Example 8d.

${ }^{16}$ Exceptional sources that consider stylistic variation in voicing include Bill Dobbins, The Contemporary Jazz Pianist, vols. 1-4 (Jamestown, RI: GAMT Music Press, 1978); and John Mehegan, Jazz Improvisation, vols. 1-4 (New York: Watson-Guptill Publications, 1959-1965). A less thorough, non-style-specific source is Mike Tracy, Jazz Piano Voicings for the Non-Pianist (New Albany, IN: Jamey Aebersold Jazz, 1998).

${ }^{17}$ For more on qualitative descriptions of intervals in voicings, see Dobbins, vols. 2 and 3.

${ }^{18}$ Dobbins, vol. 2, 12. The next sections of this paper attempt to substantiate this widely held view from a psychoacoustic perspective. 
3. "Harsh-sounding" intervals_-particularly small intervals in low registers, and the minor ninth in any register-produce higher levels of tension, and in stable chords are generally used only when less sonorous euphony is intended. ${ }^{19}$ See Examples 8c and 8e.

4. Aside from the lowest chord tone (often played by the bassist), the main chord tones in a voicing are played in a limited range around middle C. ${ }^{20}$ Example $8 \mathrm{f}$ demonstrates two voicings that clearly do not conform to this guideline.

$\underline{\text { Idiomatic }}$

a)

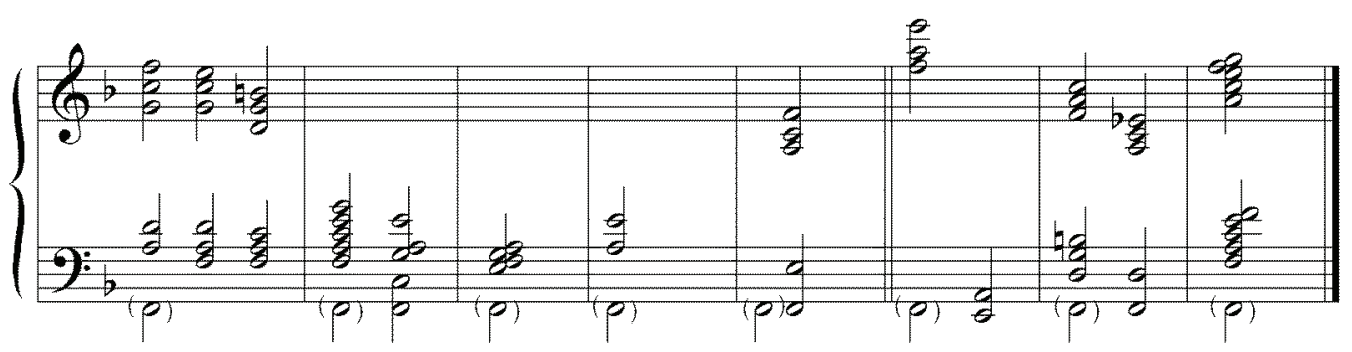

a) voicing in $4^{\text {th }}$, then two with combinations of intervals (different dialects).

b) voicing in $3^{\text {rd }}$, then one with notes registrally displaced (more common).

c) voicing in $2^{\text {nd }} \mathrm{s}$ (useful only when succeeding a more tense dominant cluster)

d) successful minimal voicing with just $3^{\text {rd }}$ and $7^{\text {th }}$.

e) effective voicing creating more tension due to interval of minor $9^{\text {th }}$.

f) important chord tones out of range; next has small interval in low register.

g) two voicings with obscured or destroyed harmonic function; extensions appear below triad tones, and both voicings include minor $9^{\text {th }}$ intervals.

h) excessive duplication of chord tones, especially root, plus minor $9^{\text {th }}$ interval.

Example 8. Illustrations of voicings: idiomatic and poor voicings.

\footnotetext{
${ }^{19}$ Some jazz pedagogues are emphatic about this guideline, even though its effective use is entirely contextual. See Jerry Coker, Improvising Jazz (Englewood, Cliffs, NJ: Prentice-Hall, 1964), 24. ${ }^{20}$ In jazz piano sources, limits of range vary widely but tend to be unnecessarily prescriptive. See, for example, John Mehegan, vol. 4, 50ff; and Ligon, 278.
} 
5. Extensions (ninths, elevenths, and thirteenths) usually appear at least an octave above the root, and elevenths and thirteenths are rarely placed below any members of the core triad. ${ }^{21}$ Example $8 \mathrm{~g}$ demonstrates two functionally ambiguous voicings that do not follow this guideline.

6. Stable members of a voicing need not be doubled, and the most effective voicings tend to be economical. ${ }^{22}$ Pianists, however, can often exaggerate the voicings of closing sonorities to create a wash of sound. Example 8h, a voicing with excessive duplication of chord tones, would be less effective in the midst of a piece and more effective and plausible at its conclusion.

Analysts should not rely too heavily on such guidelines to evaluate harmonic treatment in specific cases, given a plethora of contextual factors. But the guidelines do illuminate the dynamic progression of stable and unstable harmonies, and can and should be used in combination with the variety of tools outlined below.

An important effect of the prohibition against the minor ninth interval in stable chord voicings is that certain pitch classes will not appear under normal conditions. Because the tones of the triad-the core of all tonal jazz dialects-are inherently stable, the pitches a minor ninth above them are not permitted as possible chord tones, and are thus inherently unstable. The flat-ninth and flat-thirteenth (or flatsixth) are excluded as members of a stable chord because the root and fifth are present in major and minor triads. Because of the third of the triad, the eleventh is excluded in stable major chords and the natural tenth (or third) is excluded in stable minor chords. Further, the flat-seventh is excluded in the added-sixth dialect (though not vice versa) and the natural-seventh is excluded in the blues dialect. These relationships are shown in Example 9. Pitch classes that are excluded as potential chord tones in stable harmonic contexts are restricted in any octave, not just the octave in which a minor ninth above a dialect tone would appear. ${ }^{23}$ This does not mean that jazz pianists are prohibited from using such unstable voicings. Thelonious Monk, for example, regularly employs minor ninth intervals to create a unique and intentionally "dissonant" effect even in resolution chords. But generally

\footnotetext{
${ }^{21}$ This guideline is distilled from examples found in a variety of jazz piano sources, including Dobbins, vol. 2, 12. Note that in this study, thirteenths are understood only as dissonant chord tones that appear in the same chord as a minor-seventh interval, while sixths are consonant intervals in a chord without a minor-seventh interval.

${ }^{22}$ Dobbins writes: "Every note in a voicing, whether it contains four notes or eight, should have a reason for being there." Dobbins, vol. 2, 12. See also Steven Strunk, "Harmony," In The New Grove Dictionary of Jazz, ed. Barry Kernfeld (London: Macmillan, 1988), 162.

${ }^{23}$ One could speculate on the reasons for this. The triadic tones are reinforced in every octave within the overtone series. Also, flat ninth, eleventh (in major), and flat thirteenth—as chord tones of the dominant tritone substitution-have dominant-functioned tendencies. Regarding the dialect tones, the minor ninths above the sixth and flat seventh would create dialect ambiguity; and as for the minor triad, the minor ninth above the flat third would create modal ambiguity.
} 
speaking, the appearance of minor ninth intervals in any octave greatly destabilize a sonority. ${ }^{24}$

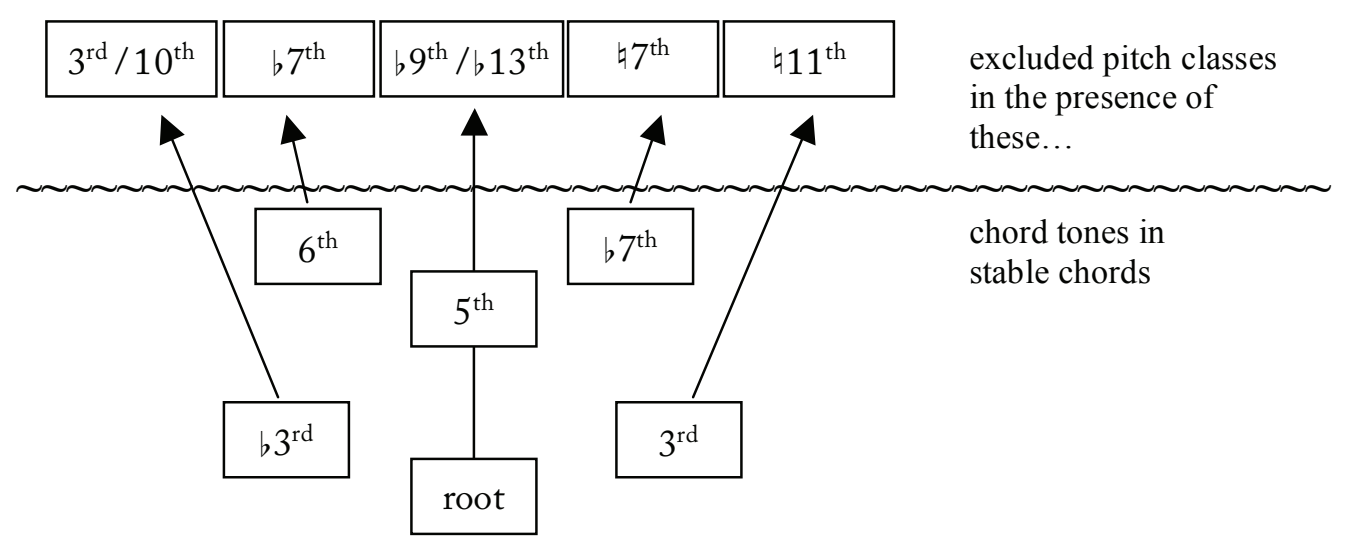

Example 9. Contextually destabilizing tones due to presence of minor ninth.

Note that the pervasive use of the dominant seventh with flat ninth-V7(b9) - is an essential part of the distinction between stable and unstable harmonies; this chordal and functional dissonance must resolve to a more stable tonic chord. Even in a major blues minor-seventh dialect, where the major-minor seventh chord is a common stable chord, the appearance of the flat ninth (as opposed to the major ninth, sharp ninth or no ninth at all) serves as a kind of weather vane of functional allegiance.

How a chord is configured - or voiced - has profound psychoacoustic implications. Lawn and Hellmer claim: "The series of pitches generated above the fundamental pitch comprise the overtone or harmonic series that serves as the basis for deriving chord extension tones and constructing acceptable chord voicings. ${ }^{25}$

\footnotetext{
${ }^{24}$ Most of these claims are supported by recent literature in jazz scale theory, addressing harmonic function and restrictions against pitch-class intervals (irrespective of register). Also of note is the constraint against chords with two consecutive semitones. See especially James Kurzdorfer, "Outrageous Clusters: Dissonant Semitonal Cells in the Music of Thelonious Monk," Annual Review of Jazz Studies 8 (1996): 184-85; Jeff Pressing, "Towards an Understanding of Scales in Jazz," Jazzforschung/Jazz Research 9 (1978): 25-35; and Dmitri Tymoczko, "The ConsecutiveSemitone Constraint on Scalar Structure: A Link between Impressionism and Jazz," Intégral 11 (1997): 135-79.

${ }^{25}$ Richard J. Lawn and Jeffrey L. Hellmer, Jazz Theory and Practice (Los Angeles: Alfred Publishing, 1993), 24. Regarding chordal extensions, the flat seventh, ninth, and sharp eleventh most clearly correspond to members of the overtone series. The terms "overtone series" and "harmonic series" refer to the same phenomenon; this study uses the former term to avoid confusion caused by the adjective "harmonic," which pertains to harmony.
} 
Strunk is more specific when he writes: "Voicings in general follow the structure of the overtone series: larger intervals below smaller." ${ }^{26}$ This guideline is an important feature of much composed common-practice music as well as tonal jazz. Some jazz piano sources describe the qualitative effect of specific voicings on the euphony, stability, harmonic clarity and appropriateness of the chord, thus relating voicing to sensory consonance.

One of the longest-running debates in music theory concerns the relevance of the overtone series to musical practice and the understanding of consonance (and thus stability). Natural Law theory, now largely discredited, links consonance directly to mathematical ratios formed by sound wave frequencies. Norman Cazden writes: "In its most general axiomatic form, the Natural Law theory states that consonance results from the ratios of small whole numbers." ${ }^{27}$ In his Harmonielehre of 1911, Schoenberg defines "consonances as the closer, simpler relations to the fundamental tone, [and] dissonances as those that are more remote, more complicated." ${ }^{28}$ Schoenberg is rooting his approach to harmony in Natural Law theory, but he is fully aware that any conception of consonance rooted in the overtone series is problematic. ${ }^{29}$ In scientific writings of the past hundred years, psychoacoustic studies that address sensory consonance have raised the level of discourse regarding the overtone series, and proponents of Natural Law theory are still vocal in recent writings in music theory. ${ }^{30} \mathrm{~A}$ few theories of sensory consonance correlate to the guidelines of voicing, although these psychoacoustic factors pertain less to the realm of science than to musical style.

Example 10 is excerpted from a book by John Mehegan; "A" stands for "Figure 1 " in his example, and " $\mathrm{B}$ " stands for "Figure 2."

\footnotetext{
${ }^{26}$ Strunk (1985), 102.

${ }^{27}$ Norman Cazden, "The Definition of Consonance and Dissonance," International Review of the Aesthetics and Sociology of Music 11/2 (1980): 128.

${ }_{28}^{28}$ Arnold Schoenberg, Theory of Harmony, translated by Roy Carter (Berkeley: University of California Press, 1978), 21.

${ }^{29}$ Schoenberg writes: "From this point of view it is thus of little importance for the explanation of harmonic problems, whether science has already refuted the function of overtones or only raised some doubts...I can make the attempt with so much the more confidence since, as far as I know, no one has yet refuted the theory beyond all doubt; and since no man is able to examine and prove everything himself, I, too, have to get along with the existing knowledge as long as I may and can believe in it. Therefore, I will proceed in my study from the possibly uncertain overtone theory because what I can deduce from it seems to agree with the evolution of the harmonic means." Schoenberg, 20.

${ }^{30}$ For example, consider William Thomson, Tonality and Music: A General Theory (San Marino, CA: Everett Books, 1999); the review of Thomson by Murray Dineen, Music Theory Spectrum 23/2 (Fall 2001): 248-50; and their subsequent colloquy together, Music Theory Spectrum 24/2 (Fall 2002): 307-10. Some jazz theory writers infer Natural Law theory as well, such as Ligon, 52.
} 
A)

B)

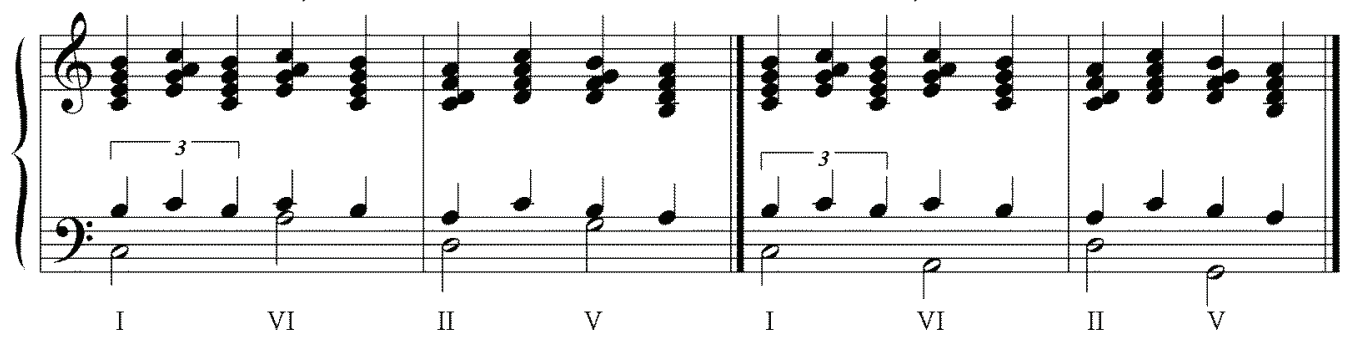

Example 10. Preferred voicings of Mehegan.

Mehegan comments:

[A] will sound better if played as in [B]. Here the depth of the roots adds a sonority missing in [A]. The student should strive to utilize the deepest roots possible without, of course, "breaking" the chord. ${ }^{31}$

Even though both patterns are acceptable (A follows the "locked-hands" or "Shearing-style" approach), a general consensus holds that voicings should have wider spacings in the lower register of the chord. Thus the voicings of the second and fourth chords of the example are favored in B over A. Considering the bass to be the generating fundamental of a complex tone, the $\mathrm{B}$ voicings also have greater correspondence to the overtone series. Example 11 highlights the second and fourth chords of Example 10, and displays the overtone series of the notes $A$ and $G$ in three different octaves. Comparing the overtone series based on G3 with the $\mathrm{G}$ dominant-seventh chord voicings, we find only one other pitch (G4) in common. But comparing the series based on $\mathrm{G} 2$ with the same voicings shows two additional pitches in common: the triad tones D4 and B4. Thus, having a bass note an octave lower is a closer simulation of the overtone series, and, at least according to Mehegan, "sounds better."

The overtone series based on G1 presents an even closer correlation with the $G$ dominant-seventh chords: all the chord tones are represented in the overtones (including the out-of-tune seventh partial represented by filled-in noteheads, but not the ninth partial). The final bass note of Example 10 (G2) maps onto the second partial. Mehegan's rule that chords feature the "deepest roots possible" suggests that $\mathrm{G} 1$ would be a better bass note, if the hand could reach it. A double bass, however, could play the G1, the optimal bass note for overlap with the overtone series.

${ }^{31}$ Mehegan, vol. 3, 152 (Lesson 48). 


\begin{tabular}{|c|c|}
\hline Mehegan's chords: & fundamentals with overtones: \\
\hline Ex. 10A Ex. 10B & $\begin{array}{lll}\text { a) } A 3 \& \text { G } 3 & \text { b) } A 2 \& \mathrm{G} 2 & \text { c) } A 1 \& \mathrm{G} 1\end{array}$ \\
\hline
\end{tabular}

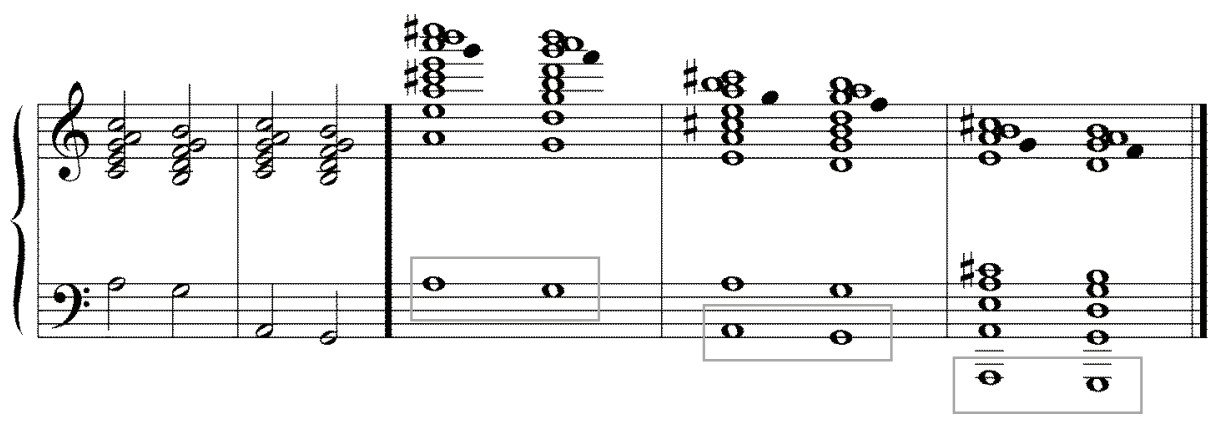

Example 11. Comparing voicings with the overtone series.

Thus far in Example 11 we have aligned the overtone series only to a dominant chord, not to a tonic. But if resonance is indeed a desired feature in voicings, this principle can be applied to any sonority. ${ }^{32}$ Turning to the A minor-seventh chords in Example 11, the association of chord tones and overtone resonance still holds, except for the presence of the minor third, which does not appear in the corresponding overtone series. Historically, Natural Law theory has had difficulty accounting for the minor mode and regarding minor chords as equivalent to major. In one explanation, Helmholtz puts forth that a minor triad is a "darkened" (Getrübter) major triad. ${ }^{33}$ In this view, the minor triad is a modification of the natural major triad, functioning in a similar way but sonically inferior. This understanding has resonance with jazz practice: major is used far more than minor in tonal jazz, largely because of repertoire. Also, jazz has traditionally made use of flexible tuning, not only with out-of-tune instruments, but more significantly with the use of bent and "worried" blue notes modifying the third and seventh in particular. ${ }^{34}$ Thus, if the third can mimic the fifth partial within a range of flexible tuning in practice, the minor mode can again be viewed as a modification of major, at least in terms of sonic analogy. Minor-mode endings can make reference to the

\footnotetext{
${ }^{32}$ For a similar analysis of voicing in Debussy, see Gary W. Don, "Brilliant Colors Provocatively Mixed: Overtone Structures in the Music of Debussy," Music Theory Spectrum 23/1 (Spring 2001): 61-73.

${ }^{33}$ See Hermann Helmholtz, On the Sensations of Tone, translated by Alexander J. Ellis (New York: Dover Publications, 1954); summarized in Gerhard Wuensch, "Hugo Riemann's Musical Theory," University of Western Ontario Studies in Music 2 (1977): 110.

${ }^{34}$ The music-psychological term tolerance, which accounts for differences in pitch, is used simplistically by Chailley to explain the flexible tuning of the seventh partial. Jacques Chailley, Historical Treatise of Harmonic Analysis, translated by Sidney Kleinman (Paris: Alphonse Leduc, 1986), 19.
} 
overtone series, but cannot produce the same resonating effect found in majormode endings. ${ }^{35}$

Example 12 presents three cases of "pyramiding," a classic ending paradigm in which sustained tones of the chord are played in a non-simultaneous sequence, mimicking the overtone series with generally larger intervals at the bottom and smaller ones at the top. Russo explains that this technique "provides a sense of motion, which can be useful enough, especially at the end of a passage that is melodically and harmonically complete, but yet needs another rattle of the drum." 36 He goes on to note, "Resonance is an additional advantage of non-simultaneous chords," providing a fuller, louder sound. ${ }^{37}$ Examples $12 \mathrm{a}$, b, and c demonstrate pyramiding for the three primary dialects. Example 12a is an added sixth (with ninth), and Example $12 \mathrm{~b}^{38}$ is a blues seventh (with additional colortones). In both cases, note how every tone corresponds with the overtone series of the lowest bass note sounding, with additional upper octaves. Example $12 \mathrm{c}$, however, replaces $\mathrm{E} b 4$ (resembling the out-of-tune seventh partial) with E4 to accommodate the majorseventh dialect.

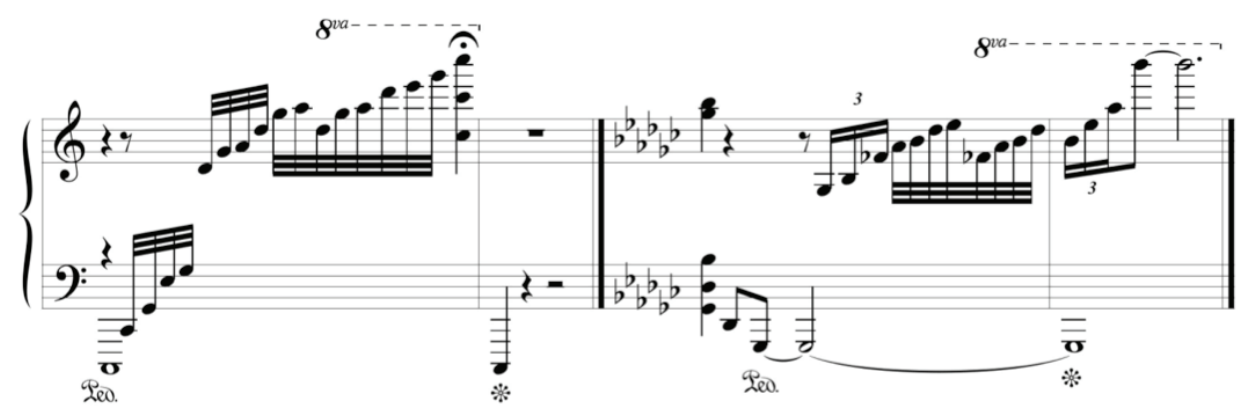

Examples $12 \mathrm{a}$ and $12 \mathrm{~b}$. Pyramiding closing sonorities that correspond to the overtone series. Teddy Wilson, "I'm Yours" (1946); and Art Tatum, "St. Louis Blues" (1933).

\footnotetext{
${ }^{35}$ Helmholtz comments on the inferior resonance of the minor third: "...this is a source of difficulty in the final chord. For this reason we find almost all popular dance and song music written in the major mode; indeed the minor mode forms a rare exception." Helmholtz, 294. Of course there are many exceptions in world musics, and Helmholtz's bias towards Germanic musical traditions is clearly evident here.

${ }^{36}$ William Russo, Jazz Composition and Orchestration (Chicago: The University of Chicago Press, 1968), 272-74. Slonimsky similarly refers to the technique of Pyramidenakkord in Nicolas Slonimsky, Perfect Pitch: A Life Story (Oxford: Oxford University Press, 1988), 174.

${ }^{37}$ Russo, 278.

${ }^{38}$ Art Tatum, The Art Tatum Collection, transcribed by Brent Edstrom, text by Ronny S. Schiff (Milwaukee: Hal Leonard, 1996), 99.
} 


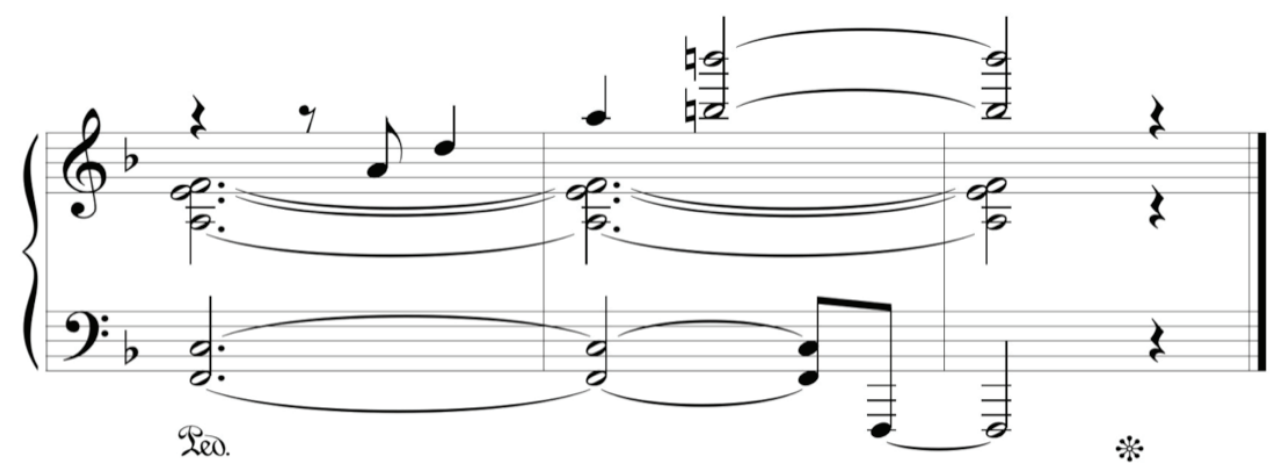

Example 12c. Thelonious Monk, "All Alone" (1957).

In such endings, virtually any pitch class can be present in a high register, emulating an upper partial of the overtone series, as long as it does not distract from the tonal prominence of the stable chord tones. Example 12c introduces the sharp eleventh (a registrally shifted and "out-of-tune" eleventh partial of F1) as a colortone expansion of the major-seventh dialect. It is no accident that Monk's righthand pyramiding ends on this color tone, emphasized by its octave. As an idiomatic rhetorical gesture, the sharp eleventh exaggerates the closing sonority for tonal emphasis, superimposing a color tone on top of a sustained, stable sonority supported by a prominent root in the bass. Such tonal hyperbole can impose normally unstable tones upon consonant sonorities without destabilizing them.

The inherently unstable tones of flat sixth, flat ninth and natural eleventh can also be incorporated into a closing sonority - a common practice in big band charts, though less common in jazz piano. In such cases, tonal hyperbole helps account for special effects, such as the bitonal effect in Example $13 \mathrm{a}^{39}$ : alternating triads based on the third and sixth include two inherently unstable tones ( $\mathrm{E}$ and $\mathrm{B}$ ). Example $13 \mathrm{~b}^{40}$ also features an inherently unstable tone, a sharp-eighth/flat ninth, which could be explained either as tonal hyperbole or as an intentional semitonal cluster. ${ }^{41}$

${ }^{39}$ Hampton Hawes, Hampton Hawes Collection (Milwaukee: Hal Leonard, 2002), 26.

40 Thelonious Monk, Thelonious Monk Plays Standards, vol. 1 (Milwaukee: Hal Leonard, 2002), 45.

${ }^{41}$ Kurzdorfer argues that [012] clusters are not appropriate as simultaneities in tonal jazz, even though Monk can incorporate them into "his uniquely anachronistic approach to the blues." Kurzdorfer also claims that Monk uses these highly dis sonant cells as "consonances." Kurzdorfer, 181-201 (especially 185). 


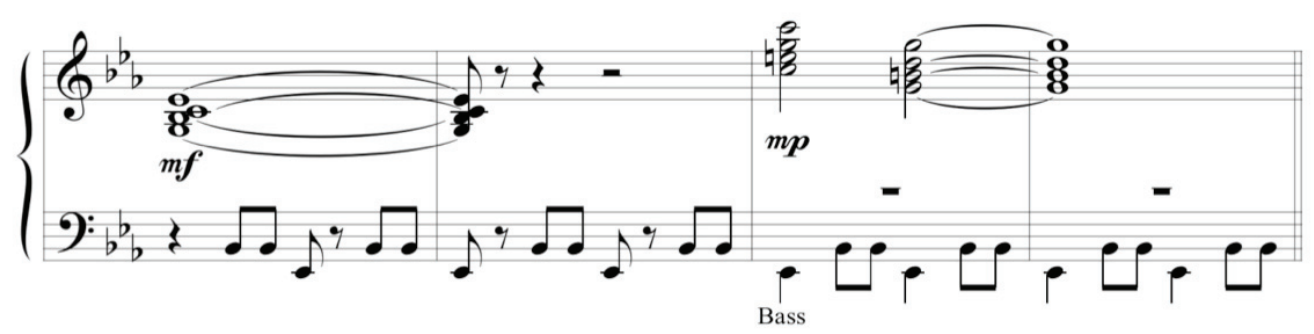

Example 13a. Hampton Hawes, ending to "Autumn in New York (December 3, 1955). These measures are followed by two additional statements of $C$ and $G$ major chords over the $\mathrm{E} b / \mathrm{B}$ b ostinato bass.

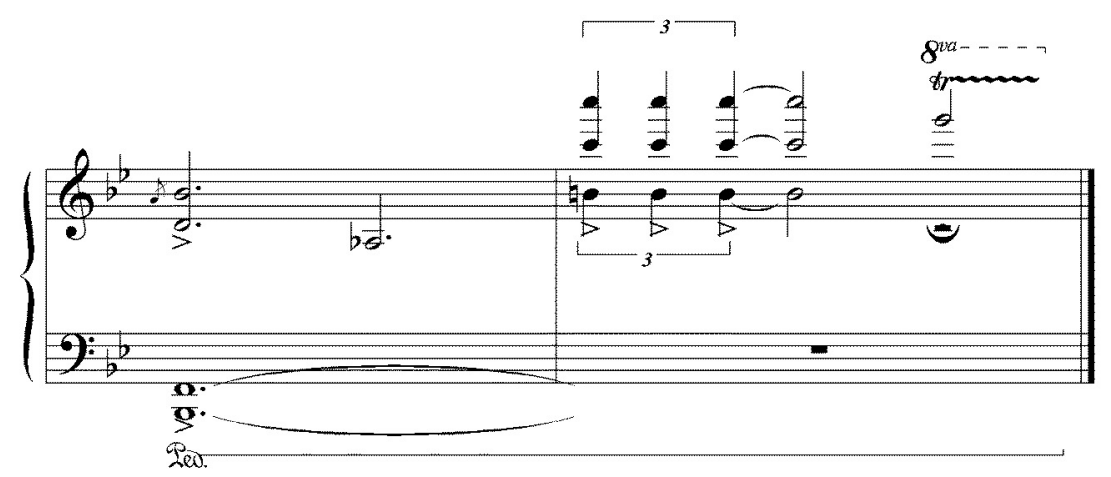

Example 13b. Thelonious Monk, ending to "Everything Happens to Me" (October 31, 1964).

Hyperbole can also explain certain "big endings," such as the final three "hammer blows" ${ }^{12}$ in Bill Evans's performance of "What is This Thing Called Love?" recorded December 28, 1959, and shown in Example 14. Evans's left hand plays a conventional voicing of a tonic $b 10 / / 67$ chord. The invoked blues dialect can also accommodate the $G$ (the fifth) and $G b$ (an enharmonically spelled sharp eleventh), but the remaining note in the right hand (besides the tonic) is a sharp-eighth/flatninth, an inherently destabilizing tone. It is important to note, however, that Evans's right hand exactly emulates the physical shape of his left hand, with a low

42 "Three hammer blows" is a rhetorical closing sign in Classical era compositions. See Kofi Agawu, Playing with Signs: A Semiotic Interpretation of Classic Music (Princeton, NJ: Princeton University Press, 1991). 
white note topped by two black notes of the same interval; the right hand adds an additional tonic pitch. The right hand simply transposes the digital pattern of the left hand by a minor tenth, and this gestural hyperbole accounts for the $\mathrm{D}$ b. Tonal hyperbole is also present here in a certain sense: the $\mathrm{E} b$ in the final $\mathrm{C}$ chord (played by the left-hand thumb) serves as the new root for the right-hand blues-seventh chord, creating an octatonic collection (also called a diminished scale in jazz theory). This right-hand $b 10 / b 7$ chord, itself based on a blue note $\mathrm{E} b$, not only exaggerates the closing harmonic rhetoric in terms of gesture and sonority, but also the effect of the blues-seventh dialect itself.

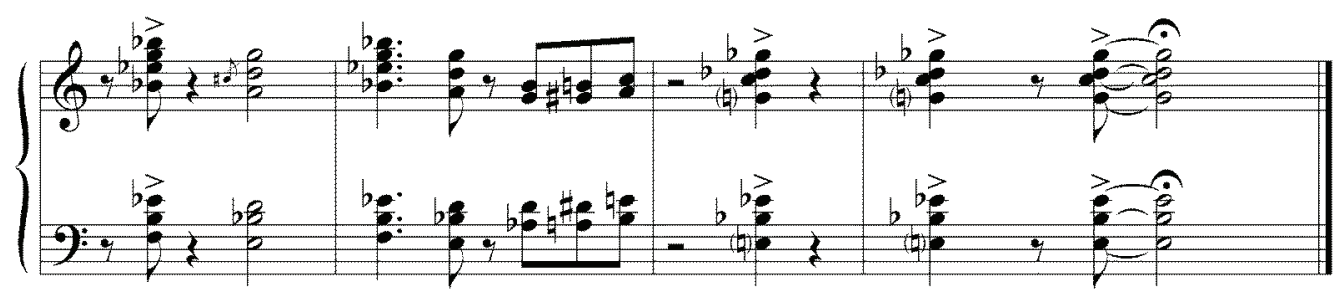

Example 14. Bill Evans, ending to "What is This Thing Called Love?" (December 28, 1959).

Pedagogical books on jazz piano and arranging for ensembles discuss many practical applications of voicing, including how register and intervallic spacing affect the stability of a chord. This in turn determines how the chord can be used, and whether it has appropriate sonorous euphony at syntactically stable moments.

Each instrument has different timbral characteristics in each register. In his discussion of "swing chords," Mehegan cites the notes E3 and C5 as "the normal limits of the 'middle' area of the keyboard most suitable to create the tonal resonance of these chords." ${ }^{33}$ Dobbins adds to the discussion of range by noting that close-position voicings are ineffective in registral extremes: "A close position voicing in a high register may sound too harsh, while a similar voicing in a low register may sound muddy. In general, the more extreme the register used, whether high or low, the more open the voicings should be for a clear and distinct sound."44 Of course such comments refer more to chord usage within a piece, not its final sonority.

These observations concerning voicing and register have a basis in psychoacoustics, not only with the overtone series but also the critical band, defined by David Butler as "the frequency range within which two signals compete for the same

\footnotetext{
${ }^{43}$ Mehegan, vol. 3, 31. "Swing chords" are weak-beat chords played by the left hand using the swing-bass technique.

${ }^{44}$ Dobbins, vol. 2, 11.
} 
receptor cells on the basilar membrane" of the ear. ${ }^{45}$ The critical band is a significant factor in perceiving euphony in dyads, and varies based primarily upon the register of the two pitches. The highest sensory dissonance occurs when notes are separated by an interval of a quarter of the critical band, and sensory consonance occurs at the critical band itself and beyond. ${ }^{46}$ In the range around middle $\mathrm{C}(\mathrm{C} 4)$ and higher, where the critical band is around a major third, sensory consonance is found highest at precisely this interval. ${ }^{47}$ Voicings that feature seconds are therefore less euphonious (earlier in this section, cluster voicings were aurally characterized as "tense"). Interestingly, in upper registers, the critical band will be a second, thus diminishing the tense quality of cluster voicings. Standard keyboard comping occurs below these upper registers, however, as noted in Example 8 and its accompanying text. At lower frequencies the critical bandwidth is greater, reflecting the musical practice of avoiding thirds at low frequencies in favor of octaves or wider intervals. ${ }^{48}$ When applied to chords, the critical band closely relates to how well a chord "blends," and thus affects perceived consonance. ${ }^{49}$

Preferred voicing arrangements tend to follow these features of the critical band in keyboard and ensemble contexts. Kynaston and Ricci write: "As a general principle a chord sounds best when the largest intervallic gap is at the bottom of the chord." They go on to advise that the lowest interval of the chord (besides the octave) should be a fifth or seventh, and not a third, "in order to create a clear sense of chord identity and function." ${ }^{50}$ Although the seventh is not a consonant interval in an acoustic or common-practice musical sense, it is obviously a crucial intervallic component to jazz harmony. In this case, sonorous euphony-which recommends against the "consonant" major third in a low register, but for the "dissonant"

\footnotetext{
${ }^{45}$ David Butler, The Musician's Guide to Perception and Cognition (New York: Schirmer Books, 1992), 224.

${ }^{46}$ For an early discussion of this phenomenon, see E. Zwicker, G. Flottorp, and S. S. Stevens, "Critical Band Width in Loudness Summation," Journal of the Acoustical Society of America 29 (1957): 548-57; updated in Eberhard Zwicker and Ernst Terhardt, "Analytical Expressions for Critical-Band Rate and Critical Bandwidth as a Function of Frequency," Journal of the Acoustical Society of America 68 (1980): 1523-25. The critical band has also been applied to analysis of chords in R. Plomp and W. J. M. Levelt, "Tonal Consonance and Critical Bandwidth,” Journal of the Acoustical Society of America 38 (1965): 556-60.

${ }^{47}$ Butler, 83.

${ }^{48}$ Plomp and Levelt, 556.

49 "The perceptual integration of components from different notes is called blending. In general, the better a chord blends, the more likely it is to be perceived as a single sonority, with a single, well-defined root; and the more consonant it sounds." Richard Parncutt and Hans Strasburger, "Applying Psychoacoustics in Composition: 'Harmonic' Progressions of 'Nonharmonic' Sonorities," Perspectives of Nerw Music 32/2 (Summer 1994): 93.

${ }^{50}$ Trent P. Kynaston and Robert J. Ricci, Jazz Improvisation (Englewood Cliffs, NJ: PrenticeHall, 1978), 142.
} 
seventh-seems more important than the common-practice laws of intervallic consonance. Register limits the use of the recommended fifths and sevenths as the lowest intervals, however, because they "tend to neutralize themselves if they get too low.” Example 15 reproduces Kynaston and Ricci’s Example 2, showing chords (marked with asterisks) that are "questionable as viable voicings because of their extremely low register...[and] too dense with overtones to be usable in most situations." ${ }^{51}$ These warnings, according to Liscomb and Hodges, are supported by studies in psychoacoustics:

Any two partials (other than a unison) that fall within a critical bandwidth add to the total dissonance. This is significant, because it suggests that roughness occurs not only as a result of interference between fundamental frequencies, but can occur between any (or all) of the harmonics of a complex tone. ${ }^{52}$

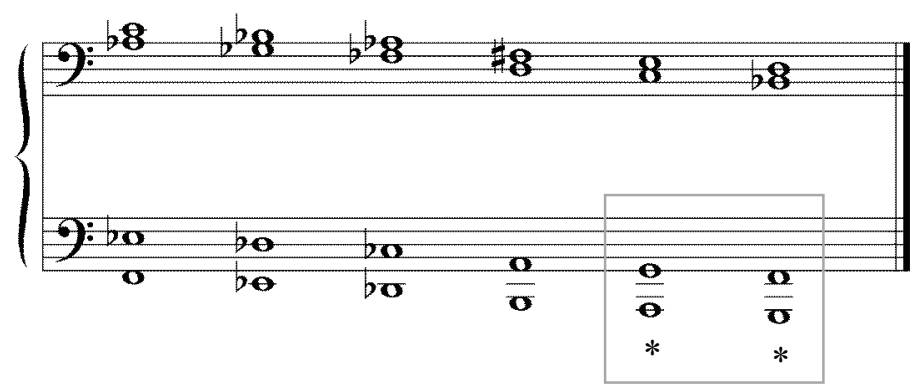

Example 15. Kynaston and Ricci; asterisks show minor-seventh voicings that are too low.

This relationship between critical band and voicing seems to hold true at least indirectly. Pease and Pullig note that voicings in seconds create "a thick, dissonant effect..., [but] as other intervals are included, the voicing opens up and the density decreases." ${ }^{53}$ They also recommend that seconds only be used above a certain register-any lower and the sound becomes too muddy. Graham Collier suggests specific lower limits for seconds through sevenths, as shown in Example 16; some of these lower limits vary from those suggested by Kynaston and Ricci. What is consistent among sources, however, is a recognition that lower limits for intervals

\footnotetext{
${ }^{51}$ Kynaston and Ricci, 143.

${ }^{52}$ Scott D. Liscomb and Donald A. Hodges, "Hearing and Music Perception," in Handbook of Music Psychology, ed. Donald Hodges (San Antonio, TX: IMR Press, 1996), 108. This claim was demonstrated in W. Hutchinson and L. Knopoff, "The Acoustic Component of Western Consonance," Interface 7/1 (1978): 1-29.

${ }^{53}$ Ted Pease and Ken Pullig, Modern Jazz Voicings: Arranging for Small and Medium Ensembles (Milwaukee: Hal Leonard, 2001), 93-94.
} 
do exist, and that limits for fifths are lower than thirds, which are lower than seconds.

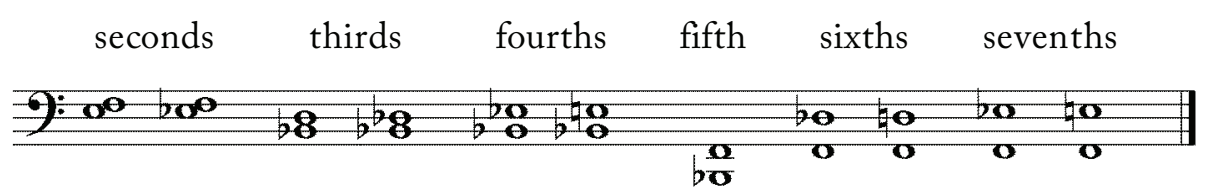

Example 16. Collier's lower limits for intervals in voicings.

Chords are often naïvely deemed consonant simply because of syntax and chordtone membership. When the factors of voicing, texture and sonorous euphony are taken into consideration, however, it becomes clear that chords are actually perceived in gradations of tension and release. These factors can spark active listeners to reinterpret a provisionally stable chord as unstable. And if listeners perceive a stable chord as too euphonious, they may consider it too weak to properly fulfill its function of resolution in a given jazz style. As Parncutt and Strasburger write: "Consonant sounds are not necessarily preferred to dissonant sounds," adding that "Optimal dissonance... depends to a large extent on the musical experience and taste of an individual listener." ${ }^{54}$ These factors also assist analysts in identifying underdetermined dialects, tonal hyperbole, and the participation of dialect tones and color tones. The point is not to reduce the identification and measuring of stability and instability to rigid scientific formulas, but rather to assist in interpreting the functional role and stylistic appropriateness of harmonies in their musical context.

\section{EXPLANATORY MODELS}

The opening section of this paper introduced three principal harmonic dialects that generally serve more effectively than triads at moments of syntactic repose in tonal jazz. These harmonic dialects are defined by their contextually stable dialect tone, which is a fully functional chord tone. ${ }^{55}$ Color tones, while serving as stable and harmonious members of a chord, are less elemental than dialect tones and more structurally extraneous to the chord (primarily in terms of voice leading). This

\footnotetext{
${ }^{54}$ Parncutt and Strasburger, "Applying Psychoacoustics in Composition, 92.

${ }^{55}$ In discussing the role played by stable extensions (roughly comparable to "dialect tones") in chords, Henry Martin has argued that tones such as added sixths participate in voice leading and all other functional aspects of harmony but cannot serve as the bass in an inversion. Henry Martin, "Early Dissonance into Jazz Consonance: The Added Sixth Chord," paper delivered at the 26th Annual Meeting of the Society for Music Theory, 2003.
} 
conception of dialects is adduced from tonal jazz but overlaps to some extent with harmony in the chromatic music of the late nineteenth century. Harrison writes:

A chord with amplified root [greater than a triad] offers the same sense of unity through harmonious proportion that marks the major and minor consonant triads. That is, the arrangement of chord tones is such that it is difficult and even undesirable to pick out one or more as superfluous to the structure of the chord...In some respects, these chords sound like colored triads, but what would be considered coloring agents participate actively in both voice-leading and harmonic structure. ${ }^{56}$

Harrison's "chords with amplified root" are similar to "harmonic dialects," simply in that tones beyond the triad are true members of the chord. But the relative consistency of stable sonorities in tonal-jazz practice allows for the development of more precise theoretical models.

This study concludes by presenting two graphic models. The first model, illustrated in Examples 17-22, ${ }^{57}$ examines the "harmonious proportion" of the various dialects and their suffixes by outlining the intervallic bandwidths between triadic members. These bandwidths are then subdivided with pitch classes that can potentially serve as chord tones. This model closely relates to the overtone series, deriving potential chord-tone memberships by "overtone approximation," while also complying with various voicing constraints. Although the term "bandwidth" denotes a continuum of frequencies between two boundary frequencies, the tonal theory considers only the twelve pitch classes in equal temperament. Thus the model derives potential chord tones by determining which equal-tempered notes fall near the frequency of the partial that actually bisects the overtone nodes. In other words, the resulting chord tones are merely harmonic approximations. The second model, illustrated in Examples 23 and 24, outlines the normative roles that these tones can play in consonant chords for the three principal dialects and two modes.

In each of the three principal dialects, one additional chord tone is added to the triad. The added tone is larger than a fifth and smaller than an octave, thus appearing within the intervallic space between the fifth and the octave. Example 17 depicts two bandwidths that bisect the octave: modal bandwidth, from the root up to the fifth, and dialect bandwidth, from the fifth up to the root. Each bandwidth is asymmetrical in pitch-class space (seven and five semitones), so further subdivision cannot create intervals of equal proportion, at least on a piano tuned in equal

${ }^{56}$ Daniel Harrison, "Dissonant Tonics and Post-Tonal Tonality," slightly modified version of a paper read at the Music Theory Society of New York State, April 28, 2002, 8. http://pantheon.yale.edu/ dh287/research/DisTonic.pdf, accessed January 25, 2009.

${ }^{57}$ These examples adapt a schematic for a chord with amplified root used by Harrison, in his Example 8. 
temperament. As Harrison writes, optimal subdivision will tend to locate "two points that are as far apart as possible from the bandwidth boundaries and thus avoid the dangers of proximity dissonance that produces intense beating and harshness." 58

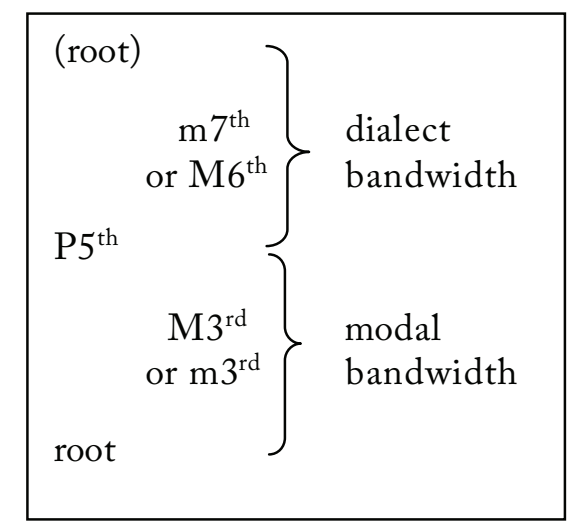

Example 17. Modal bandwidth and dialect bandwidth.

Within the lower, modal bandwidth, the two possibilities for chord tones relate to the modal options, major and minor. The overtone ratio of 4:5 results in 386 cents, which is the major third in just tuning. In equal temperament, the major third is equivalent to 400 cents and the minor third is equivalent to 300 cents; thus the 4:5 ratio more closely resembles the major third, while the minor third is the closest discrete pitch on the lower side of the ratio. While both major and minor thirds roughly bifurcate the modal bandwidth, the actual tuning of the third-as sung or played on instruments without fixed pitches - is often variable or treated as a blue note. (On the piano, crunched notes approximate the effect.) The major triad is nonetheless more resonant and, perhaps as a byproduct, more commonly used, especially as the core unit of a chord tower. In the upper, dialect bandwidth, two of three possible dialect tones are illustrated; the major seventh is excluded. Both the major sixth (900 cents) and minor seventh (1000 cents) approximate the ratio 7:4 (969 cents, corresponding to the seventh partial), which occurs midway within the span between the fifth and the octave. The minor seventh is only somewhat more resonant than the major sixth in equal temperament.

The added-sixth dialect became less prominent during or shortly after the bop period of the mid-to-late 1940s. The more strident major-seventh dialect arose as a reaction against both the added sixth, with its "sweet" harmony, and the use of the

${ }^{58}$ Harrison, "Dissonant Tonics," 8. 
major-minor seventh as a stable (and tonic) chord for many contexts. ${ }^{59}$ Example 18 illustrates this new dialect option in the dialect bandwidth. The major-seventh dialect does not preclude using the added sixth, and both can be used in close proximity or even simultaneously with dialect mixture. The major seventh is not placed near the middle of the dialect bandwidth, but it originated as a reaction against the major sixth, which is placed near the middle. Further, the major-seventh dialect does not break the two voicing contraints-the minor-ninth interval constraint and the consecutive-semitone constraint-discussed further below. The ninth and eleventh extensions can function as color tones or as dialect tones. These suffixes arose after the establishment of the added-sixth and blues-seventh dialects, but independently of the major-seventh dialect. Because ninths and elevenths fall outside of the octave, they are sometimes viewed with theoretical suspicion. In jazz discourse, however, they have been accepted as chord tones in their own right.

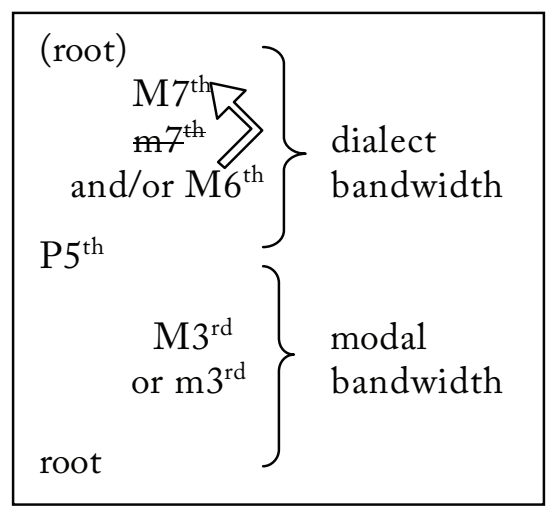

Example 18. The major-seventh dialect as an aesthetic reaction against the other dialects.

The "overtone approximation" model seen in Examples 17 and 18 can be expanded to illustrate the use of these suffixes as dialect tones or color tones. Example 19 adds a suffix bandwidth an octave above the modal bandwidth. As indicated by the curved arrows in the example, the suffix bandwidth depicts the further subdivision (or "filling in") of the modal bandwidth, in a manner comparable to the overtone spectrum. This suffix bandwidth shows that an augmented (sharp) eleventh can appear in either a major or minor consonant chord, but the perfect eleventh is available only in minor. Between the major third (400 cents) and the

${ }_{59}$ These changes of musical style are well documented in the jazz literature. The recognized functional association of dominant with the major-minor seventh chord led some jazz musicians to avoid the blues dialect for moments of syntactic repose in many tonal situations. 
perfect fifth (700 cents), the perfect eleventh (500 cents) and augmented eleventh (600 cents) equally approximate the eleventh partial (551 cents). The perfect eleventh is not available in a major chord, however, because of the minor-ninth interval constraint. Two forms of the minor-ninth constraint are relevant here: as a limitation to pitch-interval inclusion (for example, the eleventh appearing as part of the same chord as the third); and as a limitation to pitch-class interval inclusion (for example, scale-degree $\hat{4}$ appearing in the same tonic chord as scale-degree $\hat{3}$ ).
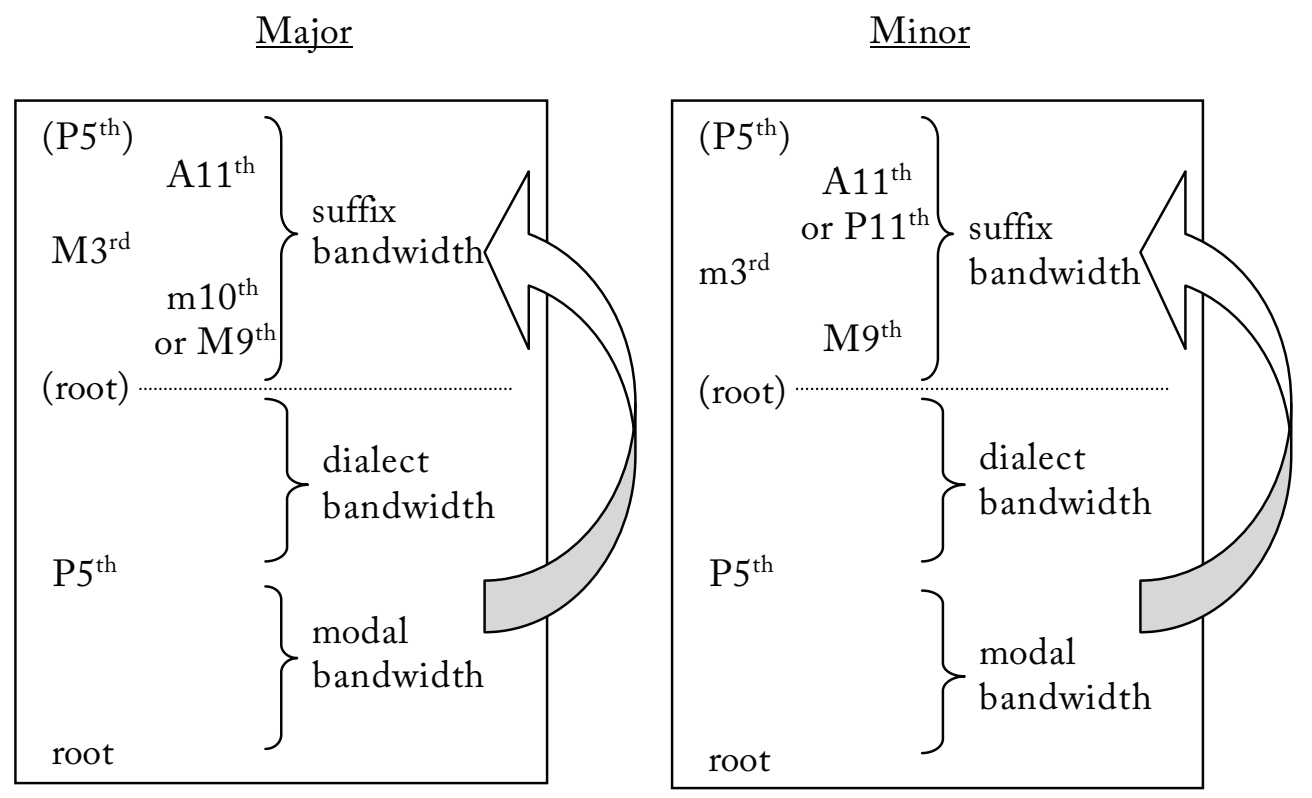

Example 19. Ninth and eleventh extensions in major and minor.

In the minor mode both the perfect and augmented eleventh are presented as options. One could object to including the augmented eleventh, however, since it is clearly not halfway between the minor third and perfect fifth. But nor is the major seventh halfway between the perfect fifth and octave. A better justification is that the augmented eleventh in a minor chord creates a non-resolving, tense-sounding sonority that somewhat emulates its major-chord cousin. An analyst may likely interpret such a minor chord as moving out of the "stable" end of the stability/instability continuum. With this caveat, the model nevertheless includes the augmented eleventh as an option in both modes, although it is much less common in minor. 
In the major blues-seventh dialect, simultaneous modal mixture can occur when the "blue-note" minor tenth appears in the same chord as the major third. The blue note should appear at least a major seventh above the major third, and due to the minor-ninth interval constraint, the major third cannot appear in the octave above the minor third (this limits the possibility of simultaneous modal mixture in minor blues). Although it is a stretch to claim that the minor tenth (1500 cents) and major ninth (1400 cents) are both acceptable pitch-class approximations of the ninth harmonic (1404 cents), the minor tenth can be relatively stable in blues contexts, and can also be justified as a stable tone by the practice of harmonizing a minor blues scale with major-minor seventh chords. Nevertheless, the minor tenth is more often a "destabilizing element" and Example 23 illustrates it as such.

Tymoczko's consecutive-semitone constraint also impacts the possibilities of chord membership in stable chords. According to this constraint, three notes related by semitone should not appear in a simultaneous collection in stable chords. ${ }^{60}$ Therefore, the major ninth and minor tenth cannot both appear in a major blues dialect and remain sounding stable; similarly, the augmented eleventh and perfect eleventh cannot both appear in a minor dialect.

Example 20 is an upwards continuation of the overtone approximation model. As shown by the arrows, the dialect bandwidth of the lower octave is opened up in the dialect-mixture bandwidth. The subdivisions within the dialect-mixture bandwidth mimic the roughly one-semitone intervals (100 cents in equal temperament) between the thirteenth and sixteenth partials. The interval between the thirteenth and fourteenth partials is equivalent to 128 cents, for example. The minor-ninth and consecutive-semitone constraints both prevent the minor sixth (or minor thirteenth) from appearing in any dialect or mode. In this bandwidth, the addedsixth dialect allows only the major seventh (major fourteenth), while the minor seventh is excluded because it creates a minor ninth with the sixth. The bluesseventh dialect allows only the major sixth (major thirteenth) to appear concurrently, because of both the minor-ninth and the consecutive-semitone constraints.

Because of the two aforementioned constraints, the only available tone that the major-seventh dialect can mix with is the major sixth above the root. Example 21 excerpts the dialect-mixture bandwidth for the major-seventh dialect, generating the same findings as the dialect bandwidth shown in Example 18. Not surprisingly, due to their similar construction, the added-sixth dialect produces the same result in the dialect-mixture bandwidth. However, in the context of the added-sixth dialect, the major seventh will typically appear as part of a chord-tower, whereas in the context of the major seventh, the sixth serves as a harmonic simplification and

\footnotetext{
${ }^{60}$ Tymoczko's constraint is partly anticipated in the work of Jeff Pressing. See Pressing, 25-35; and Tymoczko, 142.
} 
relaxation of the major seventh to its "sweet" historical origins. Example 22 summarizes the content in Examples 17-21.

$\underline{\text { Added } 6^{\text {th }}}$

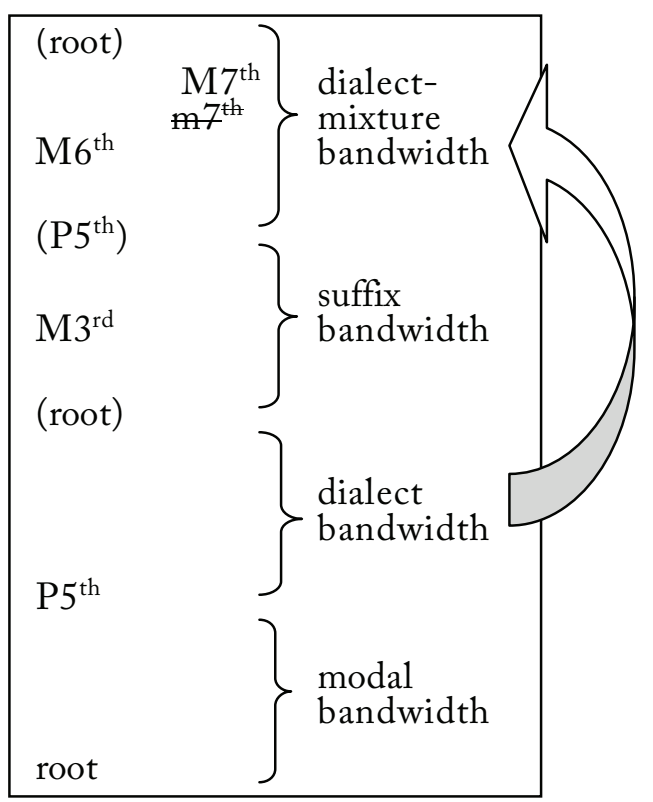

$\underline{\text { Blues } 7^{\text {th }}}$

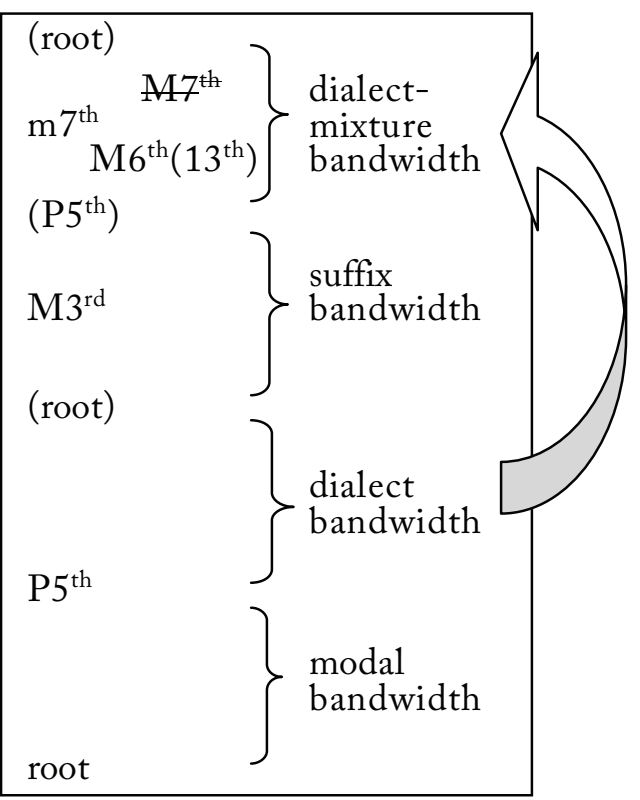

Example 20. Dialect-mixture bandwidth depicted in two-octave pitch space.

\begin{tabular}{|c|c|c|}
\hline (root) & & \\
\hline $\mathrm{M} 7^{\text {th }}$ & $\begin{array}{l}\mathrm{m} 7^{\text {th }} \\
M 6^{\text {th }}\end{array}$ & $\begin{array}{l}\text { dialect- } \\
\text { mixture } \\
\text { bandwidth }\end{array}$ \\
\hline$\left(\mathrm{P} 5^{\mathrm{th}}\right)$ & & \\
\hline
\end{tabular}

Example 21. Dialect-mixture bandwidth for the major-seventh dialect. 
Major

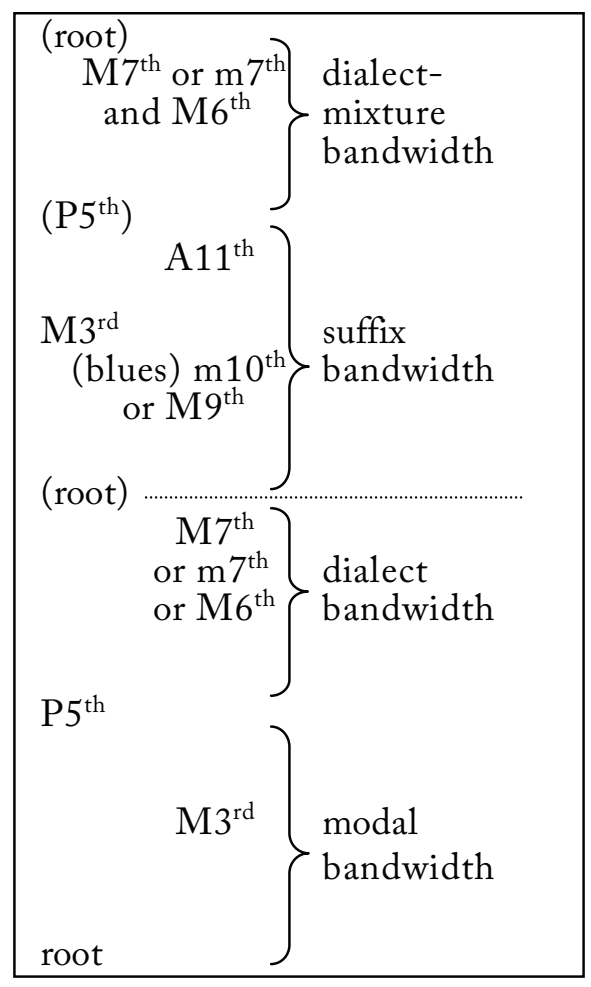

$\underline{\text { Minor }}$

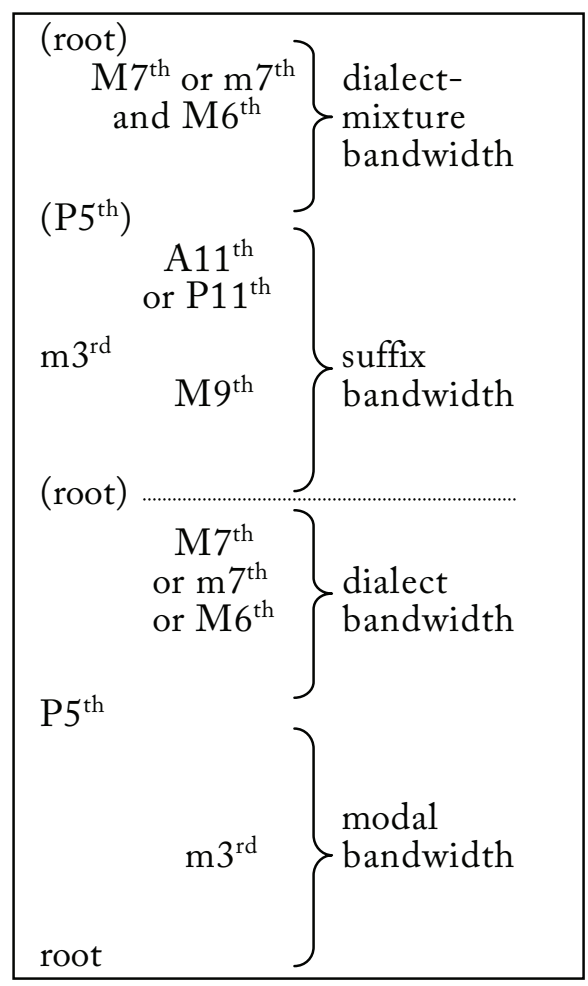

Example 22. Summaries of bandwidth models for major and minor.

The overtone approximation models in Examples 17-22 explain which intervals above the root are permitted in consonant chords in different dialects and modes, but do not model the nature of the tones themselves. Example 23, a "dialect configuration" model, depicts the configurations of stable and unstable members of a chord in the three principal dialects for a major chord. The top half of the example represents destabilizing tones that tend not to appear in consonant sonorities. The bottom half includes tones that strengthen a chord's interpretation as stable. The color tones listed for each dialect can also be found as dialect-tone suffixes, depending on musical context. In this example, all accidentals are applied to the normative diatonic set for major; natural signs are used as cautionary accidentals. 


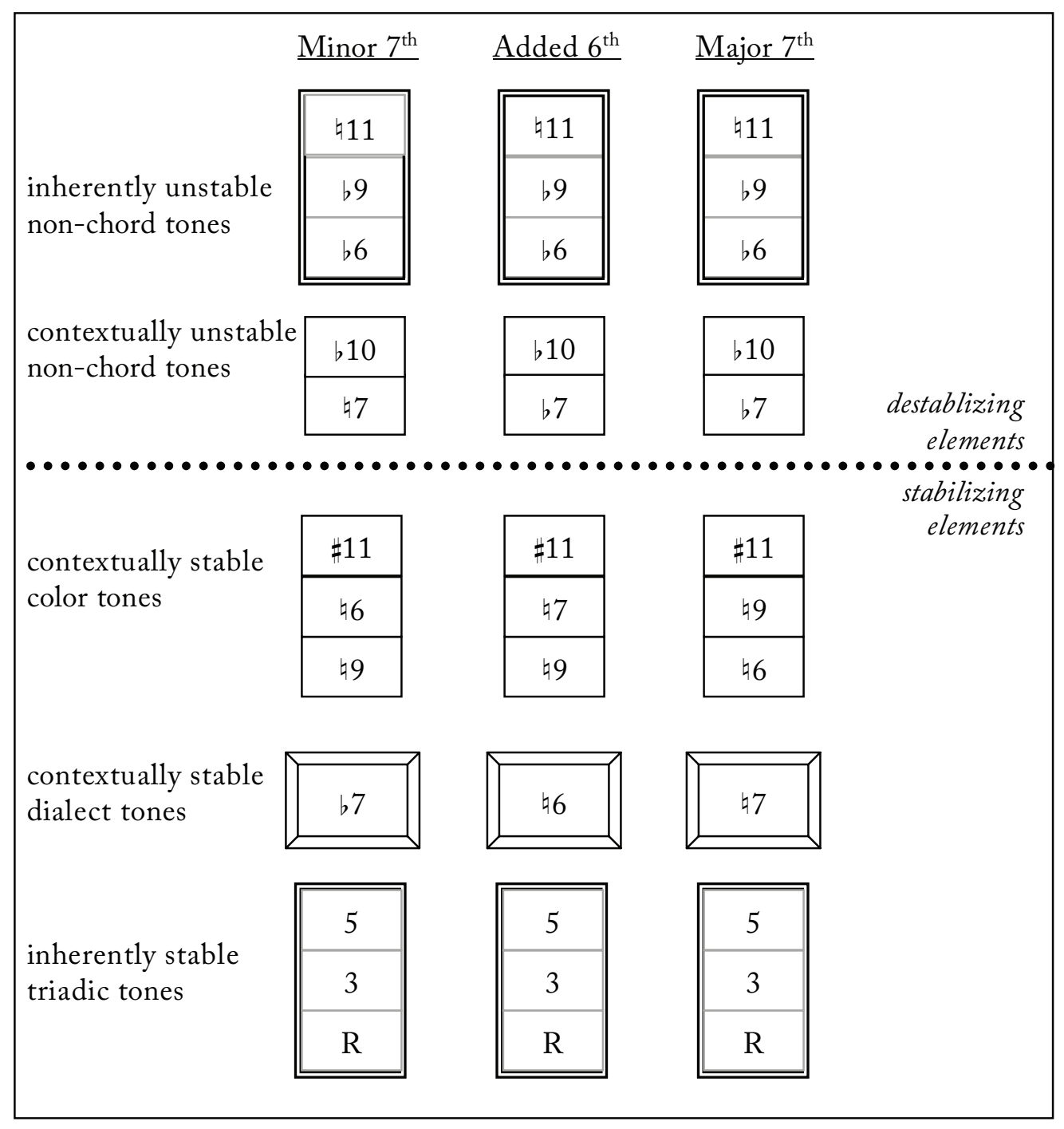

Example 23. Membership configurations of harmonic dialects: major chords.

Example 24 illustrates the configurations of dialects for minor chords, again using accidentals based upon the more normative major mode. As shown in the example, the natural eleventh or (in rare instances) the sharp eleventh can be contextually stable, but not both. In both major and minor modes, the ninths and other color tones in each of the three dialects can transform into dialect tones when the prevailing tonal context features dialect suffixes. As contextually stable tones, dialect tones and color tones can both contribute to the sonorous euphony of a chord. 


\begin{tabular}{|c|c|c|c|c|}
\hline \multirow{4}{*}{$\begin{array}{l}\text { inherently unstable } \\
\text { non-chord tones }\end{array}$} & Minor $7^{\text {th }}$ & Added $6^{\text {th }}$ & Major $7^{\text {th }}$ & \multirow{5}{*}{$\begin{array}{r}\text { destablizing } \\
\text { elements }\end{array}$} \\
\hline & Ł10 & $\natural 10$ & ฤ10 & \\
\hline & 69 & b9 & b9 & \\
\hline & $b 6$ & b6 & b6 & \\
\hline $\begin{array}{l}\text { contextually unstable } \\
\text { non-chord tones }\end{array}$ & Ł7 & b7 & b7 & \\
\hline \multirow{3}{*}{$\begin{array}{l}\text { contex tually stable } \\
\text { color tones }\end{array}$} & Ł11 (or $\# 11)$ & ต11 (or $¥ 11)$ & Ł11 (or $\# 11)$ & elements \\
\hline & $\sharp 6$ & $\measuredangle 7$ & 49 & \\
\hline & 49 & 49 & 46 & \\
\hline $\begin{array}{l}\text { contex tually stable } \\
\text { dialect tones }\end{array}$ & b7 & 46 & $\measuredangle 7$ & \\
\hline \multirow{3}{*}{$\begin{array}{l}\text { inherently stable } \\
\text { triadic tones }\end{array}$} & 5 & 5 & 5 & \\
\hline & b3 & b3 & b3 & \\
\hline & $\mathrm{R}$ & $\mathrm{R}$ & $\mathrm{R}$ & \\
\hline
\end{tabular}

Example 24. Membership configurations of harmonic dialects: minor chords.

Both the overtone approximation and dialect configuration models highlight different but important properties of the dialects. But whatever clarity they provide, these models are simply generalizations of what tones are typically found in stable jazz harmonies. Future research could spell out the use of these harmonic dialects in harmonic syntax, analyze tonal-jazz pieces for evidence, and interpret the results using tools adapted from sociolinguistics. 


\section{WORKS CITED}

Agawu, Kofi. Playing with Signs: A Semiotic Interpretation of Classic Music. Princeton, NJ: Princeton University Press, 1991.

Benward, Bruce, and Joan Wildman. Jazz Improvisation in Theory and Practice. Dubuque, IA: Wm. C. Brown, 1984.

Burbat, Wolf. Die Harmonik des Jazz, 4th ed. Munich, Germany: DTV and Bärenreiter, 1994.

Butler, David. The Musician's Guide to Perception and Cognition. New York: Schirmer Books, 1992.

Cazden, Norman. "The Definition of Consonance and Dissonance." International Review of the Aesthetics and Sociology of Music 11/2 (1980): 123-68.

Chailley, Jacques. Historical Treatise of Harmonic Analysis. Translated by Sidney Kleinman. Paris: Alphonse Leduc, 1986.

Coker, Jerry. Improvising Jazz. Englewood Cliffs, NJ: Prentice-Hall, 1964.

Dobbins, Bill. The Contemporary Jazz Pianist, vols. 1-4. Jamestown, RI: GAMT Music Press, 1978.

Don, Gary W. "Brilliant Colors Provocatively Mixed: Overtone Structures in the Music of Debussy." Music Theory Spectrum 23/1 (Spring 2001): 61-73.

Harrison, Daniel. "Dissonant Tonics and Post-Tonal Tonality." Slightly modified version of a paper read at the Music Theory Society of New York State, April 28, 2002. http://pantheon.yale.edu/ dh287/research/DisTonic.pdf

Helmholtz, Hermann. On the Sensations of Tone. Translated by Alexander J. Ellis. New York: Dover Publications, 1954.

Hutchinson, W., and L. Knopoff. "The Acoustic Component of Western Consonance.” Interface 7/1 (1978): 1-29.

Jaffe, Andy. Jazz Harmony, 3rd ed. Rottenburg, Germany: Advance Music, 2009.

Kirnberger, Johann Philipp. The Art of Strict Musical Composition. Translated by David Beach and Jurgen Thym; introduction and explanatory notes by David Beach. New Haven, CT: Yale University Press, 1982.

Kurth, Ernst. Selected Writings. Translated by Lee Rothfarb. Cambridge: Cambridge University Press, 1991.

Kurzdorfer, James. "Outrageous Clusters: Dissonant Semitonal Cells in the Music of Thelonious Monk.” Annual Review of Jazz Studies 8 (1996): 181-201.

Kynaston, Trent P., and Robert J. Ricci. Jazz Improvisation. Englewood Cliffs, NJ: Prentice-Hall, 1978. 
Larson, Steve. "The Problem of Prolongation in Tonal Music: Terminology, Perception, and Expressive Meaning." Journal of Music Theory 41/1 (1997): 101-36.

Larson, Steve. Analyzing Jazz: A Schenkerian Approach. Harmonologia: studies in music theory, no. 15. Hillsdale, NY: Pendragon Press, 2009.

Lawn, Richard J., and Jeffrey L. Hellmer. Jazz Theory and Practice. Los Angeles: Alfred Publishing, 1993.

Ligon, Bert. Jazz Theory Resources: Tonal, Harmonic, Melodic $\&$ Rhythmic Organization of Jazz, vols. 1-2. Milwaukee: Hal Leonard, 2001.

Liscomb, Scott D., and Donald A. Hodges. "Hearing and Music Perception." In Handbook of Music Psychology, edited by Donald Hodges, 83-133. San Antonio, TX: IMR Press, 1996.

Martin, Henry. "Early Dissonance into Jazz Consonance: The Added Sixth Chord.” Paper delivered at the 26th annual meeting of the Society for Music Theory, 2003.

Martin, Henry. "Schenker and the Tonal Jazz Repertory." Tijdschrift voor Muziektheorie 16/1 (February 2011): 1-20.

McGowan, James. “'Consonance' in Tonal Jazz: A Critical Survey of Its Semantic History.” Jazz Perspectives 2/1 (May 2008): 69-102.

McGowan, James. "Understanding Jazz Styles through Sociolinguistic Models." Discourses in Music 4 (Fall 2002). http://www.discourses.ca/v4n1a1.html

Mehegan, John. Jazz Improvisation, vols. 1-4. New York: Watson-Guptill Publications, 1959-1965.

Meyer, Leonard B. Music, the Arts, and Ideas. Chicago: University of Chicago Press, 1967.

Monson, Ingrid. Saying Something: Jazz Improvisation and Interaction. Chicago: The University of Chicago Press, 1996.

Parncutt, Richard, and Hans Strasburger. "Applying Psychoacoustics in Composition: 'Harmonic' Progressions of 'Nonharmonic' Sonorities." Perspectives of New Music 32/2 (Summer 1994): 88-129.

Pease, Ted, and Ken Pullig. Modern Jazz Voicings: Arranging for Small and Medium Ensembles. Milwaukee: Hal Leonard, 2001.

Plomp, R., and W. J. M. Levelt. "Tonal Consonance and Critical Bandwidth.” Journal of the Acoustical Society of America 38 (1965): 548-60.

Pressing, Jeff. “Towards an Understanding of Scales in Jazz." Jazzforschung/Jazz Research 9 (1978): 25-35. 
Russo, William. Jazz Composition and Orchestration. Chicago: The University of Chicago Press, 1968.

Schoenberg, Arnold. Theory of Harmony. Translated by Roy Carter. Berkeley: University of California Press, 1978.

Sethares, William A. Tuning Timbre Spectrum Scale, 2nd ed. London: Springer Verlag, 2005.

Slonimsky, Nicolas. Perfect Pitch: A Life Story. Oxford: Oxford University Press, 1988.

Strunk, Steven. "Harmony." In The New Grove Dictionary of Jazz, edited by Barry Kernfeld, 159-72. London: Macmillan, 1988.

Strunk, Steven. "Bebop Melodic Lines: Tonal Characteristics.” Annual Review ofJazz Studies 3 (1985): 97-120.

Thomson, William. Tonality and Music: A General Theory. San Marino, CA: Everett Books, 1999. Review by Murray Dineen, Music Theory Spectrum 23/2 (Fall 2001): 248-50; and colloquy by William Thomson and Murray Dineen, Music Theory Spectrum 24/2 (Fall 2002): 307-10.

Tracy, Mike. Jazz Piano Voicings for the Non-Pianist. New Albany, IN: Jamey Aebersold Jazz, 1998.

Tymoczko, Dmitri. "The Consecutive-Semitone Constraint on Scalar Structure: A Link between Impressionism and Jazz.” Intégral 11 (1997): 135-79.

Wuensch, Gerhard. "Hugo Riemann's Musical Theory.” University of Western Ontario Studies in Music 2 (1977): 108-24.

Zwicker, E., G. Flottorp, and S. S. Stevens. "Critical Band Width in Loudness Summation." Journal of the Acoustical Society of America 29 (1957): 548-57.

Zwicker, Eberhard, and Ernst Terhardt. "Analytical Expressions for Critical-Band Rate and Critical Bandwidth as a Function of Frequency." Journal of the Acoustical Society of America 68 (1980): 1523-25.

\section{ABOUT THE CONTRIBUTOR}

JAMES MCGOWAN is an assistant professor of music at Carleton University. He holds a PhD in theory from the Eastman School of Music, University of Rochester, and master's degrees from the University of North Texas and the University of Toronto. As reflected in his publications and presentations, his primary research interests include theory and analysis of jazz, popular music, and nineteenth-century art song.

The Journal of Jazz Studies (JJS) is published by the Institute of Jazz Studies at the Newark campus of Rutgers, The State University of New Jersey. JJS is hosted online by the Rutgers University Libraries at http://jjs.libraries.rutgers.edu. 